NBER WORKING PAPER SERIES

\title{
HEALTH, FINANCIAL INCENTIVES, AND EARLY RETIREMENT: MICRO-SIMULATION EVIDENCE FOR GERMANY
}

\author{
Hendrik Juerges \\ Lars Thiel \\ Tabea Bucher-Koenen \\ Johannes Rausch \\ Morten Schuth \\ Axel Boersch-Supan \\ Working Paper 19889 \\ http://www.nber.org/papers/w19889
}

\author{
NATIONAL BUREAU OF ECONOMIC RESEARCH \\ 1050 Massachusetts Avenue \\ Cambridge, MA 02138 \\ February 2014
}

This paper uses data from SHARE wave 4 release 1.1.1, as of March 28th 2013 or SHARE wave 1 and 2 release 2.6.0, as of November 29th 2013 or SHARELIFE release 1, as of November 24th 2010. The SHARE data collection has been primarily funded by the European Commission through the 5th Framework Programme (project QLK6-CT-2001-00360 in the thematic programme Quality of Life), through the 6th Framework Programme (projects SHARE-I3, RII-CT-2006-062193, COMPARE, CIT5- CT-2005-028857, and SHARELIFE, CIT4-CT-2006-028812) and through the 7th Framework Programme (SHARE-PREP, N 211909, SHARE-LEAP, N²27822 and SHARE M4, N 261982). Additional funding from the U.S. National Institute on Aging (U01 AG09740-13S2, P01 AG005842, P01 AG08291, P30 AG12815, R21 AG025169, Y1-AG-4553-01, IAG BSR06-11 and OGHA 04-064) and the German Ministry of Education and Research as well as from various national sources is gratefully acknowledged (see www.share-project.org for a full list of funding institutions). The views expressed herein are those of the authors and do not necessarily reflect the views of the National Bureau of Economic Research.

NBER working papers are circulated for discussion and comment purposes. They have not been peerreviewed or been subject to the review by the NBER Board of Directors that accompanies official NBER publications.

(C) 2014 by Hendrik Juerges, Lars Thiel, Tabea Bucher-Koenen, Johannes Rausch, Morten Schuth, and Axel Boersch-Supan. All rights reserved. Short sections of text, not to exceed two paragraphs, may be quoted without explicit permission provided that full credit, including $($ notice, is given to the source. 
Health, Financial Incentives, and Early Retirement: Micro-Simulation Evidence for Germany Hendrik Juerges, Lars Thiel, Tabea Bucher-Koenen, Johannes Rausch, Morten Schuth, and Axel Boersch-Supan

NBER Working Paper No. 19889

February 2014

JEL No. H55,J14,J26

\title{
ABSTRACT
}

About $20 \%$ of German workers retire on disability pensions. Disability pensions provide fairly generous benefits for those who are not already age-eligible for an old-age pension and who are deemed unable to work for health reasons. In this paper, we use two sets of individual survey data to study the role of health and financial incentives in early retirement decisions in Germany, in particular disability benefit uptake. We show that financial incentives to retire do affect sick individuals at least as much as healthy individuals. Based on 25 years of individual survey data and empirical models of retirement behavior, we then simulate changes in the generosity of disability pensions to understand how these changes would affect retirement behavior. Our results show that making the disability benefit award process more stringent without closing other early retirement routes would not greatly increase labor force participation in old age.

\author{
Hendrik Juerges

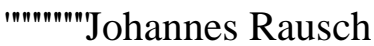 \\ एس山mMax Planck Institute \\ Schumpeter School of Business and Economics mm mfor Social Law and Social Policy \\ Rainer-Gruenter-Str. 21 [FN.01] 피 Munich Center for the Economics of Aging \\ 42119 Wuppertal \\ GERMANY \\ 피렬alienstraße 33, 80799 Munich, Germany \\ ШسWrausch@mea.mpisoc.mpg.de \\ juerges@uni-wuppertal.de \\ Lars Thiel \\ University of Wuppertal \\ एس⿴囗m Morten Schuth \\ एس山ाmMax Planck Institute \\ एسm]for Social Law and Social Policy \\ Schumpeter School of Business and Economics एس山ाMunich Center for the Economics of Aging \\ Rainer-Gruenter-Str. 21 [FN.01] \\ 42119 Wuppertal \\ GERMANY \\ thiel@wiwi.uni-wuppertal.de \\ एسயس80799 Munich, Germany \\ 핀ㄷㄴ \\ Tabea Bucher-Koenen \\ एسm|l|Axel Boersch-Supan \\ एس山ाMunich Center for the Economics of Aging \\ एس山mMax Planck Institute \\ Max Planck Institute \\ for Social Law and Social Policy \\ Munich Center for the Economics of Aging \\ Amalienstraße 33, 80799 Munich, Germany \\ एسm]for Social Law and Social Policy \\ एس山ाIAmalienstrasse 33 \\ एس⿴囗⿰丿㇄口80779 Munich \\ bucher-koenen@mea.mpisoc.mpg.de \\ एس⿴囗冂一ाGERMANY \\ एس山llland NBER \\ Шس山llboersch-supan@mea.mpisoc.mpg.de
}




\section{Health, financial incentives, and early retirement: Micro-simulation evidence for Germany \\ Hendrik Jürges, Lars Thiel, Tabea Bucher-Koenen, Johannes Rausch, Morten Schuth, and Axel Börsch-Supan}

\section{Introduction}

The aim of this chapter is to study the interrelated roles of financial incentives and health in the decision to retire early within the context of the German pension system. It continues and expands earlier research on early retirement in Germany (Börsch-Supan and Schnabel 1999, Börsch-Supan et al. 2004,2007$)$ by taking health into account in a more systematic way. Too little is yet understood about the role that health plays compared to financial incentives. In Germany at least, there is hardly any time series correlation between old-age labor force participation and objective measures of population health such as mortality rates (Börsch-Supan and Jürges 2012). Moreover, in crossnational perspective there is hardly any relationship between disability benefit (DI) receipt and average population health (Börsch-Supan 2005). On the other hand, health does seem to contribute quite a bit to explain within-country variation in early retirement at any point in time. In particular mental health problems (which are only weakly related to mortality) are increasingly found to trigger retirement at very early ages such as 45 or 50 (Börsch-Supan and Jürges 2012).

In the present chapter, we aim at a more systematic treatment of health in retirement decisions by incorporating health in a micro-simulation model of retirement. While bad health appears to be an important driver of the decision to leave the labor force within countries and in a given year, it is of course not the only one. Generous early retirement benefits - initially conceived to support older workers who are too ill to work or who have trouble finding work for a variety of reasons - may create disincentives to remain in the labor force until the regular retirement age also for healthier workers and workers who have no trouble finding work. Thus one important contribution of the present study is to estimate the effect of financial incentives on retirement behavior in a very similar way as has been done before, but to differentiate explicitly between individuals of different health states.

The question addressed is: do financial incentives to retire affect healthy individuals in the same way as they affect less healthy individuals? This is an empirical question. Theoretical predictions are ambiguous. One the one hand, one can argue that individuals' labor supply is less elastic when they 
are sick. At the extreme, individuals may not able to do any type or amount of work. Then financial incentives will not matter for the labor supply decisions, and pension reforms that reduce the generosity of early retirement provisions, for example, will only hurt those individuals financially but not affect behavior. In contrast, healthy individuals who are able to work and have a choice could be lured into retiring early if provisions are too generous.

On the other hand, it is also possible that many healthy working individuals below the regular retirement age are actually not looking into early retirement possibilities, because they are doing well and like their work. These individuals might even be ignorant about the various ways to leave work and the related financial incentives. Early retirement incentives or changes in these incentives might then have less effect than among sick individuals who have health problems that make employment more burdensome (but who are still able to work). The latter group of individuals might look into early retirement possibilities and labor supply decisions could eventually be driven by program generosity. Obviously, the answer to this research question has policy implications because pension reforms that reduce the generosity of early retirement benefits will affect the different types of individuals under both scenarios.

This is particularly interesting in the context of the German pay-as-you-go pension system that has undergone a number of changes since its inception in 1957 (described in more detail in the next section). Until the early 1980s, the system has been made more and more generous, thus creating more and more incentives to retire early. Among men, average retirement age reached its historical minimum in 1984 at only 58.2 years. Low labor market participation among older workers, together with low fertility rates, rising life expectancy and sluggish labor markets have led to falling numbers of contributors and rising numbers of beneficiaries and cast serious doubts on the financial sustainability of the system. Since 1992, in a continuous effort to save the system, both conservative and social-democratic led governments have passed a number of major and minor reforms that have reduced the generosity of the system.

Our micro-simulations, based on individual survey data spanning more than 25 years from 1984 to 2010, take into account all of these reforms which provide the institutional variation that is necessary to identify the effect of system generosity on retirement decisions. Obviously, pension reforms have many different aspects: mandatory retirement ages, credit periods for disability, replacement rates, actuarial adjustment factors, stringency of the disability award process in case of disability benefits, and so on. We try to capture as many of these aspects as possible in a single measure, the option value of postponing retirement by one year (Stock and Wise 1990), i.e. the change in expected 
discounted lifetime utility when one decides not to retire at a given age. We estimate the effect of this option value on retirement in regressions explaining annual retirement of German men and women aged 50 to 69 , overall, by health status and by education. ${ }^{1}$

We base these regressions on two sets of individual micro data: the German Socio-Economic Panel (SOEP) 1984-2010 and the Survey of Health, Ageing and Retirement in Europe (SHARE) 2004-2012. The SOEP data have the great advantage of capturing a time period during which major reforms of the German pension systems in 1992, 2001, 2004 and 2007 were conducted, see section 2.1. This institutional variation greatly helps in obtaining significant results and for the detailed study of interaction and stratification effects. The main advantage of the SHARE data is a much richer health measurement and the comparability to SHARE based estimations from other European countries. It is also illuminating to compare results within Germany between the two samples. The major disadvantage of the SHARE data is their still rather short length of just 4 panel waves. This limits the number of retirement transitions which are crucial for the econometric identification. We therefore provide the SHARE-based estimates mainly for reasons of comparability with other chapters in this volume and as a robustness check with a more refined health measure. Interaction effects, detailed stratification results and simulations of policy reforms are exclusively based on the SOEP sample.

With the estimated effect of the option value on retirement at hand, we simulate changes in the generosity of the pension system to understand how these changes would affect average retirement age. Since our specific interest in this paper is on the interrelated roles of health and financial incentives, the focus of our simulations is on disability pensions. In Germany, these pensions provide fairly generous benefits for those who are not eligible for an old-age pension (mostly individuals under the age of 60) and who are unable to work for health reasons. We describe these benefits in more detail below. Each year about 20 percent of all new pension recipients receive disability pensions and the average age of first-time DI recipients is 50 among men and 51 among women.

In an earlier micro-simulation study for Germany, Börsch-Supan et al. (2004) have modeled the effect of changes in the mandatory retirement age or changes in adjustment factors by first computing how these changes affect the option value to postpone retirement and then predict retirement behavior

${ }^{1}$ In an earlier draft of this paper we have started all analyses at the age of 45 as this seemed more appropriate for the analysis of disability benefit uptake in Germany. However, this would have compromised comparability of our results with other country analyses in this volume. Thus we decided to use 50 as starting age. However, we note that a large proportion of DI recipients enter (at least partial) retirement before that age. 
using these new option values. The focus of the current study is to model changes in the stringency of the disability pension award process. Since there is no simple quantitative measure of this important policy variable, we have chosen a somewhat different approach. We have computed option values separately for three different pathways to retirement: disability, prolonged unemployment, and regular retirement. We then combine these options values into one "inclusive" option value using the actual proportion of pensioners who have taken either path as a relative weight. Weights are based on year-sex-education cells and should reflect the perceived likelihood of being able to retire through a specific path (and thus of the actual stringency of the award process for disability pensions, for example).

In our simulations, we vary these weights and compute counterfactual option values under various scenarios. One extreme variant is to set the weight of the disability pension option value to zero. Thus we increase the stringency of the award process to infinity and effectively block the disability benefit pathway. As we show below, the predicted average retirement age will then increase by only 0.6 years among men and by 0.2 years among women. In contrast, reducing the stringency of the award process, for instance by assuming that everyone who applies would get disability benefits, reduces the estimated retirement age by more 1.5 years among men and by 2.5 years among women.

The paper is organized as follows: in the next section, we give a brief introduction into the history and the most salient features of the German public pension system. Section 3 describes our two micro data sets and documents trends in disability and early retirement in the last 25 years. In Section 4, we describe our approach to estimating the effect of health and financial incentives on retirement behavior. In particular, we discuss the computation of the continuous health index and the inclusive option value of postponing retirement. In Section 5 we show our retirement regression results, again with a focus on health and option values. Section 6 contains a more detailed discussion and interpretation of our empirical results, especially with respect to the goodness of fit of the model, and the measured incentive effect of the option value. This section also shows the results of our simulations of effect of pension reforms on retirement behavior. The final section concludes.

\section{The German pension system}

We begin this section by a short description of the German statutory public pension system (Deutsche Rentenversicherung) and its major reforms in the last 50 years. We focus on the most salient aspects, in particular those related to disability insurance and other early retirement options. 
More detailed descriptions can be found, e.g., in Börsch-Supan and Wilke (2007) and Börsch-Supan (2011). The German pension system covers 85 percent of the German workforce, most of them working in the private sector. Six percent of the workforce ( $25 \%$ of the public sector employees) are civil servants, such as police, teachers, administrators, or university professors. Civil servants have their own separate and more generous pension system, which we do not describe here. Nine percent of the workforce are self-employed who are mostly self-insured.

\subsection{History of the German pension system}

The current pay-as-you-go pension system was introduced in 1957. The basics are simple. There are two types of pensions: old-age pensions and disability pensions. Eligibility for an old-age pension begins when one reaches the mandatory retirement age (which was 65 for both men and women until recently), conditional on a minimum number of contribution years but independent of the ability to work. Eligibility for a disability pension begins when one becomes partly or fully unable to work, independent of age, but again conditional on a small minimum number of contribution years.

These simple basics are complicated by a number of variants of old-age pensions with usually lower retirement ages but stricter criteria in terms of contributions years (see Table 1). Already introduced in 1957 were old-age pensions for women and old-age pensions for the unemployed, both could be drawn at age 60 if contribution requirements were met. Thus until the first major reform of the pension system in 1972, there were only three pathways into retirement: regular old-age pensions, old-age pensions after long-term unemployment, and due to work disability. About half of all workers retired early due to disability. Since unemployment was at an historic low in the 1960s and early 1970s, retirement via unemployment accounted for only two percent of all entries into retirement. About ten percent of women retired early on old-age pensions for women. In 1972, before the major reform took effect, the average retirement age for those retiring on old-age pensions was 65.1 among men and 62.7 among women. The average retirement age on disability was about 57.8 among men and 59.8 among women (see Figure $A 1$ in the Appendix).

--- about here Table 1 ---

The 1972 reform introduced two further variants of "early" old-age pensions and thus marked a significant increase in generosity. First, workers with at least 35 contribution years became eligible for old-age pensions already at age 63 without actuarial adjustment. Second, old-age pensions for disabled workers were introduced, also conditional on 35 contribution years, with an earliest entry 
age of 62 that was later reduced to age 60 . Both options became an instant success among men, with roughly 30 percent of all workers taken either path to retirement. Average retirement ages on oldage pensions gradually decreased to 62.5 among men and 61.9 among women in 1980 . The new retirement options partly substituted for the disability pathway, and the average age among those retiring on disability benefits dropped to 54.4 among men and 57.7 among women.

The next set of reforms was enacted in 1984. First, there was an increase in generosity - aimed primarily at women - by reducing the eligibility requirement for regular old-age pensions (at age 65) from 15 to 5 contribution years. At the same time, restrictions on the eligibility for disability pension were strengthened. This included the introduction of a minimum of three contribution years in the last five years and stricter medical examinations. This part of the reform also affected primarily women, who often did not meet the stricter requirements. Hence within two years, from 1984 to 1986, the number of women retiring through the disability path decreased by 62 percent while the number of women retiring at age 65 essentially doubled.

In face of a looming demographic crisis, serious attempts to cut back on the generosity of the German pension system started in 1992. First, pension benefits were anchored to net rather than to gross wages. This change broke the vicious cycle of increasing pension benefits in response to increasing contribution rates. Second, actuarial adjustments of benefits to retirement age were introduced, albeit only gradually from 1998 onward. As intended, their introduction reduced incentives to retire early, and retirement age and labor force participation of older individuals has indeed increased since then.

Further adjustments to make the German pension system sustainable were decided in 2004 and 2007. In 2004, the pension benefit indexation formula was modified to account for demographic developments (Commission for Sustainability in Financing the Social Security Systems 2003). In 2007, a gradual increase in the normal retirement age from 65 to 67 years to be phased in between 2012 and 2029 was decided. Retirement ages for other variants of old-age pensions were increased as well. For instance, the age limit for old-age pensions for the disabled will be shifted to 65 years, and old-age pensions for women were effectively phased out.

\subsection{The benefit formula}

Pension benefits $B$ are computed as the product of four factors:

$$
B=E \times Z \times R \times A
$$


where $E$ for Entgeltpunkte (earnings points) represents relative lifetime earnings. One year of social security contributions of the average wage earner yields exactly one earnings point. Thus a worker who has entered the labor force at age 20 , worked continuously while receiving average pay, and retires at age 63 has a total of 43 earnings points. To compensate the loss in earnings due to nonemployment before becoming eligible for old-age pension, workers who retire on DI get awarded additional earnings points for each year they retire before becoming eligible for old-age pensions for the disabled (credit periods). In order to compensate DI recipients for the introduction of actuarial adjustments, credits for non-employment years have become more generous. Until 2004, full credit was awarded for each missing year until age 55 , and $1 / 3$ credit for each year between 55 and 60 . Since 2004, full credits are awarded until age 60.

$Z$ for Zugangsfaktor represents the actuarial adjustment for retirement age. Before the introduction of actuarial adjustments, $Z$ was equal to one for every pension type. Even today, adjustments are not actuarially fair. Adjustment factors were set discretionarily at 3.6\% for each year of earlier retirement (but $6 \%$ for each working year after age 65 ) and thus some 1.5 percentage points lower that than current life tables and a 3 percent discount rate would imply (Börsch-Supan and Schnabel 1999). Table 2 describes the situation in 2010, the end of the observation period in most of our empirical analyses. It shows an overview of retirement ages and adjustment factors by benefit type and retirement age. Note that disability pensions and old-age pensions for the disabled are the most generous in terms of actuarial adjustment. In contrast to all other pension types, where the $3.6 \%$ reduction is made for each year workers retire before age 65 , the pivotal age for disability pensions and old-age pensions for the disabled is 63 . Moreover, for retirement ages younger than 60 there is no further adjustment to disability benefits.

--- about here Table 2 ---

$R$ for Rentenartfaktor represents the type of benefit (worker, widow, orphan). It is 1 for workers' pensions, 0.6 for widow pensions and 0.2 for orphans. Widow and orphan pensions are partly means tested. The details are again fairly complex and we refrain from describing them here because widow pensions are not taken into account in our empirical analyses.

A for Aktueller Rentenwert represents the current average pension value. This is the amount in Euro a retiree receives for each earnings point. As described above, $A$ was anchored to gross wages until 1992 and to net wages thereafter. Since 2004, the development of $A$ also depends on the development of the system dependency ratio, i.e. the ratio of pensioners to workers. 


\subsection{Unemployment benefits at older ages}

When analyzing the role of financial benefits and health in retirement decisions, we will also take into account unemployment benefits at older ages. Retiring via unemployment has come to be an important pathway to retirement. This pathway may be attractive to some because unemployment benefits at older ages are generally more generous than those for younger unemployed. There are type 1 and type 2 unemployment benefits in Germany, UB1 and UB2 in short. UB1 amounts to 60\% (households without children) to $67 \%$ (households with children) of last net earnings for a period between 12 and 32 months, depending on age (details are shown in Table A1 in the Appendix). When UB1 expires, and workers are still unemployed, they receive UB2 for an unlimited period, i.e. essentially until becoming eligible for pensions. Until 2004, UB2 amounted to 53\% (without children) or $60 \%$ (with children) of last net earnings. In the major reform of the German welfare system in 2004 , UB2 has been turned into a lump-sum welfare payment of currently $382 €$ per month. To this lump-sum payment, benefits for housing and heating are added based on actual costs.

\section{Data and descriptives}

In this section, we introduce our two main data sources, SOEP and SHARE, describe our health measures, and provide an overview of the trends in German DI participation.

\subsection{The SOEP data}

Our main data source for detailed estimation and micro simulation is the German socio-economic panel (SOEP), an ongoing household panel survey of the German population similar in scope to the PSID (see Wagner et al. 2007 for a detailed description). The SOEP started in 1984 in West Germany and covered some 6,000 household. Since then, the sample size has been increased several times (notably after re-unification) and now consists of roughly 19,000 individuals in 11,000 households. Individual interviews are conducted with all household members aged 17 and over. The survey covers a wide range of subjects but the focus was and still is labor market experience and earnings. This includes retrospective employment histories starting at age 15 , so that is possible to reconstruct retirement pathways also ex post for years in which a panel member has not yet been interviewed. It also allows us to identify if individuals retire directly from employment or if they first go through a spell of unemployment. 
The large number of years, the large sample size and the availability of detailed employment biographies has motivated us to use the SOEP for our analysis. However, the downside of using the SOEP is the measurement of health. In the first decade of SOEP, there were hardly any questions on health. During the years, the SOEP has broadened in scope and now also includes fairly detailed health measurements. Yet in order to make use of full length of the panel, we decided not to restrict our analytic samples to years with detailed health information.

We constructed our sample using as starting point all West German respondents aged 50 to 69 in 1984 to 2009. Individuals become part of the analytic sample in the year in which they turn 50 and stay in the sample until they retire, die or are lost to follow-up in any other way. Moreover, the sample is restricted to public and private sector employees. Civil servants or self-employed are not included.

\subsection{The SHARE data}

The Survey of Health, Ageing and Retirement in Europe (SHARE) is a pan-European data set designed to analyze the process of population ageing using cross-national comparisons within Europe and between Europe, America and Asia. While SHARE currently includes 20 European countries, covering the area from Sweden to Greece and Portugal to Estonia, this paper only uses the German data. SHARE covers the interplay between economic, health, and social factors in shaping living conditions of older people. SHARE provides very detailed health measures, ranging from self-rated health over large sets of limitations in daily living and doctor-reported conditions to biomarkers and performance measures.

In wave 3, the SHARE panel data has been enriched with detailed accounts of the respondents' life histories (SHARELIFE). By integrating this retrospective view, the living conditions in the preceding decades become accessible, thus granting various insights going back as far as into childhood, especially employment histories with several anchors in which earnings are measured.

We construct a panel of respondents based on the SHARE/SHARELIFE data for East and West Germany. The information from the three panel waves (2004, 2006 and 2010/12) is combined with information on working status and income from the life histories in SHARELIFE. Since SHARE focuses on respondents older than 50 , the majority of individuals included in our sample are older than 50 years of age. We keep a small number of respondents' spouses older than 45 years. The exact way of calculating the job information from SHARELIFE is explained in section 4.3.1. 
We construct a panel of 813 individuals observed from 2004 to 2012. Of those individuals we are only keeping individuals either working in the complete observation period or transitioning from work to retirement while we observe them. We are left with 383 individuals. On average individuals are observed for 6 periods (minimum 4 years, maximum 8 years).

\subsection{Measuring Health}

We measure health by using the health index proposed by Poterba, Venti and Wise (2010), which is constructed by performing a principal component analysis using data from Wave 1, 2 and 4 of SHARE for Germany. The obtained continuous health index is computed separately for each wave and is the first principal component of 24 health indicators, see Table 3. The functional limitations in walking, carrying and pulling have the highest factor loadings.

--- about here Table 3 ---

The raw scores of the index are then used to group individuals into health quintiles in each wave. Individuals assigned to the lowest quintile have the worst health and those assigned to the highest quintile have the best health. As we are interested in the transition to retirement for a given year in the observation period, we replace the health index for years in which no SHARE survey took place with the value of the health index from the last wave relative to a given year (e.g. we took the values for the health index computed in 2004 for the health index in 2005 and so on).

In SOEP, we build our health index on three health variables that are available since the first wave of SOEP. First, there is "health satisfaction", measured on a 0 to 10 scale. This is clearly a subjective measure that appears to be similar to self-rated health and has been used as a measure of subjective health before (e.g. Riphahn 1999, Romeo Gordu 2006). Second, we have information on health care utilization - the number of doctor visits in the last three months and the number of nights spent as inpatient in a hospital in the last calendar year. Third, we combine the information in these health variables by a similar principal components analysis as for the SHARE data. Included in this computation are all SOEP respondents aged 50 to 69 from 1984 to 2010. Raw health values for each person are then converted to percentiles. In the retirement regressions below, health is added in quintiles (where low values mean bad health and high values mean good health). 
Figure 1, Panel (a) shows the average health index percentile separately for men and women aged 50 to 69. Men are on average healthier than women (at all ages) and health generally deteriorates with age. It is instructive to read this figure horizontally. For instance, we find that women reach the $50^{\text {th }}$ percentile of health at the age of about 52 . Men reach this percentile at 55 years. In that sense, one can speak of a health gap between women and men that is equivalent to being 7 years older. Panel (b) shows the average health percentile by education group jointly for men and women. This graph reflects the familiar education gradient in health (e.g. Jürges 2009, Kemptner et al. 2011). Nevertheless, the steepness of the gradient is surprising. For instance, we find that according to our index, 52 year old basic track graduates are on average as healthy as 68 year old academic track graduates, i.e. the health gap is 16 years. Moreover, the graph also suggests that the educationrelated health gap is actually increasing in age.

\subsection{Trends in DI participation 1984-2009}

We now describe the development of disability pension receipt and early retirement in general from 1984-2009. In contrast to earlier work, we use for this description survey data from SOEP. We decided not to reports trends in DI participation, i.e. the stock of DI recipients, from official statistics for several reasons: first, the official statistics are not available by age or education, or any other covariates, most importantly health. Second, a break in the official time series in 1992 (due a reallocation of pensioners across pension types) gives rises to huge spurious "reform effects" that do not reflect actual pathways.

However, using the SOEP has also its disadvantages. First, it does not show the actual pension type a retiree receives. Rather, we identify respondents who retired on disability benefits by the combination of age (younger than 60) and their self-reported labor force status (retired). At ages 60 and over, we are only able to say whether respondents draw any pension but not if this is health related. Second, since the SOEP started in 1984, we have only limited information on years before 1984. Labor force participation before the start of the panel can be approximated by labor market biographies, which are available beginning at age 15 for all respondents. However, we found the results to be quite implausible when compared to official statistics. This may be due to recall bias or sample selection issues. To avoid such problems, we decided to begin our description in 1984 and we use data from the employment biography pertaining to the last calendar year only. Third, when looking at population subgroups, the number of observations in some cells can become small and the 
aggregate statistics that we discuss in this section may become somewhat noisy. Thus it only makes sense to discuss broader trends over a number of years, not specific values for specific years.

Figure 2 shows DI participation rates over time since 1984, by sex, age groups, education groups, and health status. The average age at first receipt of a disability pension is about 50 , hence we decided to look at age groups 45 and older. ${ }^{2}$ Participation rates are measured as the proportion of respondents in the respective age groups who claim they are retired. Quite naturally, participation rates are highest in the oldest age group and lowest in the youngest age group (see panel (a)). Generally, DI participation appears to be slightly increasing over time among men at least until about 2000 and decreasing afterwards. In contrast, among women, we find decreasing participation rates until about 2000 and then again some increase.

--- about here Figure 2 ---

Panel (b) of Figure 2 shows DI participation rates by education. Education is measured by an individual's school leaving certificate according to the three different secondary school tracks in Germany: basic, intermediate, and academic track. This is the most straightforward way to distinguish education groups in the context of the German education system. After being taught together in primary school for four years, students are assigned to one of three secondary school tracks which are usually taught at separate schools. The selection process depends on a mix of formal exams, grades in primary school, recommendations by the class teacher, and parental choice. Of the three tracks, Hauptschule is the basic track leading to a basic school leaving certificate after 9 or 10 years of schooling (depending on the federal state). Realschule is a more demanding intermediate track which leads to a school leaving certificate after grade 10 . Having finished school, both students from the basic track and the middle track usually start an apprenticeship or a school-based vocational training. Gymnasium is the academic track leading to a general university-entrance diploma (Abitur) after grade 12 or 13. Earlier studies show that secondary track choice has strong implications for the entire life course (Dustmann 2004, Jürges and Schneider 2011). Our findings are consistent with the earlier studies. We observe a clear education gradient in DI participation particularly among men. However, the gradient is less clear among women. Only in the last 10 years

\footnotetext{
${ }^{2}$ Note that we are not only unable to identify DI participants older than 59 in our data, doing so will also make less sense than in the U.S. context, because many individuals older than 59 are eligible for regular pensions. However, for comparison with other countries, we show early retirement rates for the 55-64 age groups in Figure A2 in the Appendix.
} 
we observe a systematic gap between those with academic track education and those with intermediate or basic track education. One reason why we observe a clearer gradient among men might be that men with basic education often work in physically demanding jobs. The general pattern of DI participation over time among basic track graduates actually matches the temporal pattern of musculoskeletal diseases as primary diagnosis for disability benefit uptake. As shown in BörschSupan and Jürges (2012), musculoskeletal conditions were the most common primary diagnosis between about 1990 and 2000, but their relevance has greatly diminished since then.

Panel (c) of Figure 2 shows DI participation rates by health level, where health is measured by a continuous index and subsequently divided into quintiles from bad to good health (described briefly in section 3.3 above). We omit the second and fourth quintile for improved clarity of the graph. While we generally find a graded relationship between health and DI participation, with the least healthy individuals having the highest DI participation rates, the relationship appears to be highly nonlinear. Individuals in the first health quintile (i.e. those with the worst health levels) have by far the highest DI participation rates, around 15 to 20 percent. Participation rates in the third quintile are also somewhat elevated, but there is not much difference between the middle and the best quintile.

--- about here Table 4 ---

Considering the strong link between health and education, we also show DI participation rates jointly by health and education groups, see Panel (a) of Table 4, based on the SOEP data 1984-2010. Even within health groups, we find an education gradient in DI participation, and within education groups, we find a health gradient. Thus health and education interact strongly when explaining DI participation rates in Germany. The same holds for retirement rates among the 55-64 year olds (see Table $A 2$ in the Appendix).

The SHARE data exhibit a similar pattern of DI participation as in SOEP, see Panel (b) of Table 4: participation rates are much higher for the lowest health quintile and strongly decrease thereafter. However, SHARE has a lower overall participation rate for both men and women, and the difference between the first and the higher health quintiles is more pronounced. This may be due to the more precise definition of DI possible with SHARE where the type of pension is part of the question battery on benefit recipiency. Moreover, the data covers a much later sample, 2004-2012, when DI rules were less generous than between 1984 and 1995. 
To put the development of DI participation in context, we now describe the development of employment at large at older ages. This analysis is based on the SOEP data in order to depict the long-term trends. Figure 3 shows employment rates among older individuals over time, by age group, sex, education, and health. Employment among men aged 45-54 is fairly stable over time. The small ups and down reflect general developments on the German labor market, for instance high unemployment rates in the mid-1990s, which are also mirrored in the trough in employment in the 55 to 59 age groups. As shown in Table A1, unemployment benefits in this age group were particularly generous during that period. The most significant trends in employment can be found among men aged 60 to 64 . After a long decline to about $45 \%$ in the early 2000 s, they have increased steeply. This is a consequence of general improvements on the labor market but also of the labor market and pension reforms of the early 2000s. Among women, labor force participation has been continuously rising in all age groups. This finding mainly reflects rising female labor force participation among younger cohorts.

Employment at older ages exhibits a clear gradient by education. The gap in employment rates between individuals who graduated from academic track and individuals who graduated from basic track rises clearly with age. In 2009, the difference in employment rates was about 4 percentage points in the 45-49 age group but 25 percentage points in the 60-64 age group. However, the gap appears to have narrowed in the last decade, mainly because of steeply rising labor force participation rates among the less educated in the 60-64 age group.

--- about here Figure 3 ---

Labor force participation by health is also clearly graded as expected. Individuals in the healthiest quintile have the highest labor force participation rates and those in the least healthy quintile have the lowest participation rates. As with education, we find that the gap widens as individuals get older. In 2009, for instance, the percentage difference in employment rates between the healthiest and the sickest $20 \%$ in the $45-49$ age group was only 6 percentage points. In the $60-64$ age group the same difference was 21 percentage points. Note, however, that since 2000 , employment rates are increasing also among the sickest respondents in the oldest age group. 


\section{Empirical Approach}

In this section we explain our empirical approach to estimating the effects of health and financial retirement incentives on exiting the labor force and the data used for our estimations. The general regression specification is:

$$
h_{i} \equiv p\left(l_{i t+1}=0 \mid l_{i t}=1\right)=f\left(H_{i t}, O V_{i t}, X_{i t}, \varepsilon_{i t}\right)
$$

We estimate the probability of leaving employment (i.e. retiring immediately or becoming first unemployed and then retiring) in year $t+1$ conditional on working in year $t$ as a function of individual health $H$ in year $t$, of the option value of continuing to work $O V$ in year $t$, and a set of individual specific covariates: age, sex, education, occupation (SOEP only), asset income (SOEP only), household wealth, and spouse's employment status. We generally specify $f()$ as a probit model and report marginal effects. In the following, we describe the empirical specification of our main explanatory variable, the option value of postponing retirement, as well as the dependent variable, exit from the labor force.

\subsection{Pathways to retirement}

The financial incentives that are relevant in the decision to retire are summarized in the inclusive option value to postpone retirement, as described in the next subsection. The first step is to compute for each working individual the future stream of expected earnings and pension benefits that arises from each of the following pathways:

1. Continue working for another year and receive labor market income, then decide again.

2. Retire on disability benefits, receive those benefits until the regular retirement age, and then switch to a regular old-age pension. Retiring on DI includes receiving old-age pensions for the disabled.

3. Leave work and register as unemployed, receive unemployment benefits or other welfare payments until one becomes eligible for an old-age pension, especially old-age pension for the unemployed. We assume that nobody who registers as unemployed will get back into work.

4. Leave work and receive neither earnings nor welfare payments until eligible for an old-age pension. Then draw a regular pension based on ones earnings points obtained during employment. 
Thus we consider three main pathways to retirement: disability pensions, unemployment, and oldage pensions. To illustrate the value of each path in terms of pension and/or welfare benefits, Figure 4 shows in stylized form the potential benefit streams for a male worker considering retirement at age 54 as a percentage of the last net earnings. To simplify the exposition, we assume a constant average pension value. If the worker retires on DI at age 54 , he will receive about $63 \%$ percent of his last net earnings for the rest of his life. If the worker becomes unemployed, he will remain so until age 60 and then switch to old-age pensions for the unemployed. During the first year of unemployment, he will receive UB1, then UB2, which is lower than UB1. If the worker simply retires without drawing unemployment benefits or disability benefits, he will receive nothing until he becomes eligible for old-age pensions, for instance at age 65 when he has less than 35 contribution years.

--- about here Figure 4 --

\subsection{Option value calculations}

To measure the effect of pension system generosity on early retirement and disability uptake, we compute the inclusive option value of remaining one year longer in employment. "Inclusive" means that all alternative pathways to retirement are included in a single OV measure by appropriate weighting. The inclusive option value is computed in several steps.

\subsubsection{Estimating individual earnings and benefits streams}

First, we take all respondents who are between 50 and 69 years old in any year between 1984 and 2009 in SOEP and between 2004 and 2012 in SHARE, respectively. For each of these respondents, we compute, for each year and for each potential retirement age, the (expected) earnings and benefit streams from each possible pathway to retirement: disability pension, unemployment, and regular old age pension. We only consider earnings and benefit streams of the individual decision maker and do not include survivor pensions (in contrast to the US, there are no spouse benefits).

Individual earnings streams can be divided in three periods: pre-survey participation, during survey participation, and post-survey participation. Whereas we are able to observe earnings during participation directly for a certain number of years (contemporaneous earnings), we need to infer individual pre-survey and post-survey earnings by appropriate backcasts and forecasts, respectively. The key ingredients in individual earnings backcasts and forecasts are for the SOEP data: 
1. Historical average gross earning for backcasts and predicted average gross earnings for forecasts. Both historical averages and forecasts (until 2025) are derived from official statistics of the German statutory pension insurance scheme (Deutsche Rentenversicherung Bund 2012). Thereafter we project average earnings with a 1 percent real growth rate.

2. Historical average tax and contribution rates for backcasts and predicted tax and contribution rates for forecasts. These are taken from statistics published by the Federal Ministry of Finance (2013) and the German statutory pension insurance scheme (Deutsche Rentenversicherung Bund 2012), respectively.

3. Individual earnings relative to average earnings. We estimate relative earnings for each individual in our data by running a fixed effects regression of contemporaneous (gross) log earnings, separately for men and women, on a third-order polynomial in age. The individualspecific intercept ("fixed effect") from this regression measures the deviation of an individual's earnings from average earnings.

4. Individual labor market biographies dating back to age 15. These are taken from the SOEP employment calendars and biographies.

Based on contemporaneous information on earnings, backcasts and forecasts, we compute earnings of each individual $\left(\widehat{Y}_{i t}\right)$ as

$$
\hat{Y}_{i t}=\left\{\begin{array}{ccc}
E_{i t} \cdot \alpha_{i} \cdot\left(g \bar{Y}_{t}-\bar{T}_{t}-\bar{C}_{t}\right) & \text { if } & t<t^{\min (i)} \\
Y_{i t} & \text { if } & t^{\min (i)} \leq t \leq t^{\max (i)} \\
\tilde{E}_{i t} \cdot \alpha_{i} \cdot\left(g \tilde{Y}_{t}-\tilde{T}_{t}-\tilde{C}_{t}\right) & \text { if } & t>t^{\max (i)}
\end{array}\right.
$$

where $E_{i t}$ indicates whether individual $i$ was employed $(=1)$, unemployed $(=0.6)$ or out of the labor force $(=0)$ in year $\mathrm{t}$, and $\tilde{E}_{i t}$ represents future employment status. $\alpha_{i}$ is the individual specific effect obtained from the fixed effects earnings regressions; $g$ is a gender adjustment factor equal to 0.9 for women and 1.1 for men reflecting gender differentials in average earnings due to discrimination or productivity differences. $\bar{Y}_{t}$ are historical average gross earnings in year $\mathrm{t}, \bar{T}_{t}$ is the historical average tax rate in year $t$, and $\bar{C}_{t}$ is the historical average contribution rate to social security, health and unemployment insurance. Likewise, $\tilde{Y}_{t}$ are predicted average gross earnings in year $\mathrm{t}, \tilde{T}_{t}$ is the predicted average tax rate in year $\mathrm{t}$, and $\tilde{C}_{t}$ is the predicted average contribution rate to social security, health and unemployment insurance. We use the predicted social security contribution rates published by the German statutory pension system, but as predicted tax rates, we simply use the 2010 values. $t^{\min (i)}$ and $t^{\max (i)}$ are the first and last year an individual is observed in the SOEP. Earnings forecasts are made until 2035 (when the youngest cohort in our data reaches age 70). 
In SHARELIFE the respondents are asked to recall any job spell, which lasted six months or longer using the so-called Life History Calendar (see Schröder, 2011). In addition, the first wage at the beginning of each job, characteristics specific to each spell (e.g. occupation, industry, part-time work, etc.), the current wage if the respondent is still working (at the time of the interview) and the last wage at the end of the main job (if the respondent is a retiree in 2008/2009) are obtained during the course of the interview.

We use the methodology applied by Weiss (2012) to obtain the complete earnings history for each respondent for the German subsample of SHARELIFE:

1. In a first step we take the imputed current wage from wave 1 and wave 2 to replace missing values for the current wage in SHARELIFE (for employment spells which started before wave 1 or wave 2). The remaining missing values for first wage, current wage and last wage of the main job were imputed using predictive mean matching (first introduced by Little, 1988). Thus, we end up with complete data on the first job of each job spell, the current job and the last wage of the main job, which are necessary to project the annual wage during each employment spell. ${ }^{3}$

2. In a second step, we regress the logarithm of the current wage (last wage of the main job respectively) on potential labor market experience and its quadratic form, years of schooling and on characteristics which are specific to the respective employment spell, i.e. dummy variables for type of industry and for white-collar jobs. All explanatory variables are interacted with potential labor market experience and its quadratic form. ${ }^{4}$

3. The obtained estimated regression coefficients and the first wage of each job spell are then used to predict the wage at the end of each employment spell. Having the wage at the beginning and at the end of an employment spell and the length of each spell at hand we are able to calculate the annual growth of wages during an employment spell.

4. As last step, we use the growth rate to compute the wage for each year during an employment spell.

Weiss (2012) checked the validity of the wage prediction procedure using data from the SOEP. The provided evidence shows that this method for predicting wage is rather well.

\footnotetext{
${ }^{3}$ Observations were dropped for individuals whose wages at the end of the main job are coded in a foreign currency or are not codable. Amounts given in German Mark (DM) and East German mark are converted into Euro.

${ }^{4}$ Potential labor market experience is defined as the age in year $t$ minus years of education and age at school entry.
} 
Net wages are translated into gross wages by using historical tax and social security contribution rates. Earnings points are calculated by comparing gross wages to and historic average wages.

Finally, we use the same method for SOEP and SHARE to make benefit forecasts for each individual at each planning age from 50 to 69 until 2060 when the youngest cohort reaches age 100 . We use the above earnings histories to compute disability pensions, unemployment benefits (UB1 and UB2), and old-age pensions at each retirement based on the relevant legislation.

\subsubsection{The option value of postponing retirement}

To compute the option value of continuing work in utils, we first convert income from work $Y$ into utility using the instantaneous utility function $u(Y)=Y^{\gamma}$ with parameter $\gamma=0.75$. Then we convert retirement income and/or unemployment benefits B into utility using the instantaneous utility function $v(B)=(k B)^{\gamma}$ with parameter values $\gamma=0.75$ and $\mathrm{k}=1.5$, where $k$ reflects the relative value of leisure. These utility parameters are the same as in all other country chapters of this volume to ensure comparability. The choice of 1.5 is based on earlier US estimates (Gruber and Wise, 2004) and appears to be very low for European countries, see e.g. Börsch-Supan et al. (2004) who use a grid search algorithm and obtain maximum likelihood estimates between 2.5 and 3.5 for Germany. This difference is exacerbated by a lower choice of $\gamma$ than in Börsch-Supan et al. (2004).

Next we compute the expected future lifetime utility at some planning age a from retiring at any future age $R$ as

$$
E U_{i}(B)_{a}^{R}=\sum_{t=a}^{R-1} \frac{1}{(1+r)^{t-a}} s_{i t} u\left(Y_{i t}\right)+\sum_{t=R}^{T} \frac{1}{(1+r)^{t-a}} s_{i t} v\left(B_{i t}\right)
$$

where $s_{i t}$ is the conditional probability of being alive in year $t$ (obtained from life tables of the Federal Statistics Bureau), $r$ is a discount rate arbitrarily set to $3 \%$, and $B$ is one of the three types of benefits considered here. $Y_{i t}$ and $B_{i t}$ are earnings and benefits, respectively, in year $t$ at age $a+t$. The first part in eq. (4) reflects expected and discounted utility during one's working life and the second part reflects expected and discounted utility during one's retirement years. In our computations, the maximum attainable age $T$ is arbitrarily set to 100 . In $t=0$ (at some planning age), the gain in expected life-time utility from continuing working until age $R$ (compared to receiving benefit $B$ from the next period onward) is equal to

$$
O V_{i}(B)_{a}^{R}=E U_{i}(B)_{a}^{R}-E U_{i}(B)_{a}^{a+1}
$$

Thus the option value of not retiring on benefit B at some planning age $a$ is equal to the maximum gain (across all $R$ ) from delaying retirement:

$$
O V_{i}(B)_{a}=\max _{R}\left[O V_{i}(B)_{a}^{R}\right]
$$


Clearly, the larger OV at any given planning age, the stronger the incentive to postpone retirement.

\subsection{Weighting the pathways - the inclusive option value}

The option value described in the preceding subsection is computed for a specific type of benefit, i.e. for some specific pathway to retirement. However, since individuals in Germany have several options of retiring early, we want to estimate a weighted average of all option values to capture the overall incentive effect to retire. The weights should reflect the probability that either of these paths is a realistic pathway to retirement. Using the employment biographies in the German SOEP data, we estimate these weights - by year, sex, and education level - as the shares of the already retired population aged 50 to 69 who have retired through either of the following pathways.

1. Entering retirement on disability benefits (DI path). These are men and women who have changed directly from employment to retirement before the age of 60 and men who have changed from employment to retirement at age 60-63. Formally, the latter group retire on old-age pensions for the disabled, but we classify these as retired through DI:

2. Entering retirement via unemployment (UB path). These are women who were unemployed before retiring at age 60 or over and men who were unemployed before retiring at age 62 and over.

3. Retiring on old-age pensions (OA path). These are women who change directly from employment to retirement at age 60 and over and men who change from employment to retirement at age 63 and over.

We compute the inclusive option value of not retiring at age a as the weighted average of the three relevant option values:

$$
O V_{i}(a)=\pi(D I) \times O V_{i}(D I)_{a}+\pi(U B) \times O V_{i}(U B)_{a}+\pi(O A) \times O V_{i}(O A)_{a}
$$

Here, $\pi(D I), \pi(U B)$, and $\pi(O A)$ are the weights of the three pathways and $O V(D I), O V(U E)$, and $O V(O A)$ are the respective option values.

For the SHARE data, we use the same approach with two deviations:

- We also include the basic pension intended to provide a minimum standard of living ("Grundsicherung") which was introduced into the pension system in 2003. After calculating the expected earnings related pension we check if this pension is above the minimum level. If not, pension benefits are topped up to this level. 
- For all pathways we check if the respective pathway via DI or Unemployment gives higher utility than the regular old-age pension. The assumption for this procedure is that this pathway can always be chosen. Only if DI or unemployment would deliver higher utility the weighting is applied.

Figure 5, based on the SOEP data, Panel (a) shows the option values (in 10,000 utils) of not retiring from each of the three pathways at each planning age between 50 and 69, separately for men and women. Several points are worth being highlighted. First, average option values are always larger than zero, that is, given our parameterization of the utility function (standard across all country papers in this volume), continuing to work always increases expected life-time utility, even at ages 65 and older. Thus it seems surprising that anyone actually retires. This pattern is identical when looking at OVs calculated from the SHARE data (not shown here).

--- about here Figure 5 ---

The relative attractiveness of each pathway is reflected in the value of the OV conditional on age: the smaller the OV the more attractive a pathway. For men up to age 60 retiring on $\mathrm{DI}$ is the most attractive option on average, followed by unemployment and old-age pension. Considering the stylized benefit streams shown in Figure 3, this is not surprising. The increase in the DI option value at age 60 seems puzzling at first sight. The reason for this jump is that from age 60 onward individuals actually do not receive DI proper but old-age pensions for the disabled (OA-DI). In contrast to those planning to retire on DI (at ages younger than 60), individuals planning to retire at any future age on OA-DI will not be credited further earnings points for the years they were unable to work.

A summary of the present discounted value of the earnings and benefit stream from either pathway is shown in Panel (b) of Figure 5. These figures clearly illustrate the generosity of both DI and UE. The present discounted value of the earnings/benefit stream even falls with age because of the increase in pension benefits. The present discounted value of the old-age pension options rises continuously until the arbitrarily chosen end of the decision period.

Figure 5 also show the inclusive option value by age and education (Panel (c)) and by age and health (Panel (d)). There are substantial differences in option values across education groups, particularly among men. Basic track graduates have lower inclusive option values (thus higher incentives to retire) than intermediate or academic track graduates at every age. Of course, this difference is due mainly to disparities in earnings streams across education groups. The variation across health 
quintiles is not as large but it is clearly present. Individuals in the lowest health quintile (worst health status) have lower option values or higher early retirement incentives. This reflects differences in earnings across health groups, i.e. an income gradient in health. Our analysis does not say anything about whether low earnings are due to bad health or rather bad health due to low earnings as this is beyond the scope of this paper.

\section{Results}

Our analytical SOEP sample consists of a panel of 4,109 working individuals with a total of 21,000 observations. The SHARE sample is much smaller with 813 individuals contribution to 2,118 observations in 4 waves. As mentioned before, each individual becomes part of the analytical sample at age $50^{5}$ and remains in the sample until he or she self-reports as retired, becomes 69 years old, dies or is lost to follow-up for other reasons.

\subsection{The effect of retirement incentives}

Before discussing the results of our retirement regressions, we describe our dependent variable. We consider as a retiree anyone who has self-reported being retired during the observation period. However, we consider as the year of retirement the year in which the individual stopped working. To give an example: if an individual claims to be retired for the first time at age 60, but was employed for the last time at age 57 , the individual is said to have retired at the age of 58 , no matter if the individual was unemployed or out of the labor force or both during the two years between ending employment and becoming a retiree.

In SHARE we are using self-reported retirement from the life history calendar. Respondents are asked for which reason they left their job. If they said „I retired" and this is the last job-spell we observe, they are considered retired. This definition is identical to the other SHARE-based studies in this volume.

Table 5 shows the probit regression results (marginal effects) of five specifications of the explanatory variables for the SOEP and the SHARE data, respectively. Model (1) includes a linear age effect and no covariates, (2) included age dummies and no covariates, (3) includes a linear age effect and

\footnotetext{
${ }^{5}$ In SHARE, a small number of spouses of respondents are between age 45 and 50.
} 
covariates, (4) includes age dummies and covariates, and (5) includes sex-specific age dummies and covariates. Model (4) is the common specification in this volume, of which we discuss the quantitative results. In general, results are clearer when using age dummies, but the qualitative findings are robust across the different specifications.

The OV coefficient reflects the percentage point effect of increasing the inclusive option value by 10,000 utils. Note that these are marginal effects evaluated at the means of the explanatory variables. The effect is highly significant in all specifications based on the SOEP data. This also holds for the estimates based on the SHARE data when age is specified as a set of dummy variables (columns 2 and 4). A 10,000 util increase in the option value reduces the probability of retirement by approximately 4.2 percentage points in the SOEP data and by 2 percentage points in the SHARE data. Put in relative terms this means that $73 \%$ increase in the option value relative to the overall mean of 13,770 reduces retirement hazards by about $80 \%$ percent compared to the overall average of 5.3 percent in the SOEP data. The SHARE-based estimate is substantially smaller: a similar $76 \%$ increase in the option value relative to the overall mean of 13,065 reduces retirement hazards by only about $36 \%$ percent compared to the overall average of 5.5 percent.

The smaller effects in SHARE compared to SOEP may have various reasons. SHARE includes the topping-up of low pensions via social assistance ("Grundsicherung im Alter") which makes the option value flat for individuals with low pensions. Moreover, the samples are different: SHARE includes respondents from East Germany and has a substantially later sample. Finally, the precision of measurement is different. SHARE has a more encompassing health measure, while SOEP has more precise earnings histories, see below.

The numbers in square brackets in Panel (a) show the average effect of a one standard deviation change in the inclusive option value - computed as the average predicted retirement probability when the option value is 0.5 standard deviations larger than its actual value minus the average predicted retirement probability when the option value is 0.5 standard deviations smaller than its actual value, averaged across all observations. The estimates indicate that a one standard deviation increase in OV reduces retirement rates by about 5.9 percentage points or nearly $100 \%$ of the average. The difference between the effect sizes found for the two alternative specifications can be partly explained by a strongly non-linear (concave) relationship between OV and retirement hazards. The larger the option value at baseline, the smaller the effect of one util. 
Yet another estimated specification of the relation between the inclusive option value and the probability to retire can be found in Table 6 , shown for the SOEP data only. Here we show the effect of the utility gain if labor force participation is continued until the optimal age relative to the utility when retiring at the planning age. In other words, this is the percentage gain in future lifetime utility from choosing the optimal retirement age instead of retiring now. This measure has a few advantages over the absolute number of utils. For instance, absolute option values very much reflect the individuals' income level. A 10,000 utils option value of postponing retirement may thus mean a lot more (have a stronger incentive effect) to a low income than to a high income worker. Related to this, the relative utility gain might be more useful in international comparisons when income levels differ across countries.

The coefficients reported reflect the effect size of a one hundred percent lifetime utility gain from postponing retirement. Again, results show a decline in retirement rates when the lifetime utility gain from postponing retirement rises. Our estimates show that doubling this gain is linked with a 1.3 percentage point or 20 percent decrease in retirement hazard rates. Note however, that standard errors are much larger relative to the point estimates than before, so that the coefficients are significant at the $10 \%$ level only.

\subsection{The effect of health}

We now turn to the effect of health on retirement rates. Table 5 shows the coefficients of health quintile dummies with those in the worst health quintile being the reference group. Respondents in higher quintiles are in better health. Our results clearly show that health has a significant relationship with retirement rates. Healthier individuals have lower retirement rates. The results also show that the relationship is highly non-linear. Respondents in the baseline quintile have about 1.2 to 1.5 percentage points higher retirement hazard rates than those in the second to fifth quintiles (among which there is no big difference) in the SOEP sample. The SHARE sample exhibits a substantially higher effect of health on retirement, indicating that respondents in the baseline quintile have about 2.1 to 3.2 percentage points higher retirement hazard rates than those in the second to fifth quintiles. It is noteworthy that the non-linear shape of the health effects is very similar for both the SOEP and the SHARE sample. Compared to the overall average retirement rate of 5.3 (8.3) percent this suggests having a severe health shock and moving from the fifth to the first health quintile would increase retirement probabilities by more than 20\% (35\%) in SOEP (SHARE, respectively). "Mild" health shocks, e.g. moving from the fourth to the second health quintile do not seem to have any 
effect on retirement rates. The larger marginal effects in the SHARE data compared to the SOEP, together with the substantially smaller effects of the option value, may reflect the more encompassing health measure in the SHARE data. The SOEP-based estimates of the financial incentives may therefore be an upper bound. Since the earnings histories in the SOEP are probably a more precisely estimated than those based on the SHARELIFE data, the SHARE-based estimates of the financial incentives may rather be a lower bound.

\subsection{The effect of financial incentives by health status}

Having established independent effects of health and financial incentives on retirement rates, it is natural to ask whether the two interact. Specifically, the question is whether healthier individuals are more or less responsive to financial incentives. Casual reasoning suggests that the labor supply of sick individuals should be less elastic than the labor supply of healthy individuals simply because sick individuals' choices are constrained by bad health. On the other hand, one might argue that individuals who are in bad health and consider early retirement might be more responsive to financial incentives than healthy individuals who have no plans to retire early. Both effects are not mutually exclusive and may even cancel each other out.

--- about here Table 7 ---

Table 7, based on the SOEP data, shows the effect of the inclusive option value on retirement rates separately for each health quintile. This is estimated from separate retirement regressions for each of the health quintiles. We have estimated the effect of a 10,000 util increase, of one within-quintile standard deviation increase and of a one hundred percent increase in future lifetime utility.

The qualitative results are robust across all specifications, but not across different measures of the early retirement incentives. Let us begin by looking at the marginal effect of a 10,000 util increase in the option value to postpone retirement, i.e. when the incentives are specified in absolute terms. Here, we find the biggest effect of the inclusive option value in the first health quintile. The estimated effects decrease up to the fourth quintile and then increase again (slightly). These findings appear to be consistent with the notion that sick individuals for whom early retirement is a more salient option are also more influenced by the financial incentives. At this point one should also keep in mind that average option values are positive everywhere and that those in good health have particularly high option values. Thus making early retirement more or less attractive will probably not make a large difference to them. In contrast, those in worse health have lower option values anyway, 
so that changes in option values matter more. The opposite mechanism - sick individuals being so constraint in their labor supply decisions that financial incentives do hardly matter - seems less prevalent.

The estimated effects of a one within-quintile standard deviation change in the OV are qualitatively similar to those discussed in the preceding paragraph. However, the decline in the OV effect across quintiles is weaker. This may be partly due to the fact that the OV standard deviation is larger among the healthy (and richer) than among the unhealthy. In contrast to the findings above, where the sickest quintile stood out, it seems that it is now the healthiest quintile that much less responsive to early retirement incentives than the rest. Finally, when looking at another relative incentive measures, the percent gain in lifetime utility, we find no clear pattern. If anything, the incentive effect seems to be slightly increasing with health status.

It is of course unfortunate that different specifications yield somewhat different conclusions. The choice of specifications is rather ad hoc, and we have no theory that would tell us which specification to prefer. We believe a fair summary of the results shown in Table 6 is that there is hardly any evidence that the labor supply of the sickest quintile is the least elastic at the extensive margin. Rather, depending on specification of the incentive variable, their reaction to financial incentives is at least as strong as the reaction of the healthier quintiles - if not stronger.

\subsection{The effect of financial incentives by education level}

Our final set of results, again based on SOEP data, relates to differences in retirement behavior by education groups. As noted above, a good way to distinguish education levels in Germany is by type of school leaving certificate or type of secondary school track attended: basic track, intermediate and academic track. We have already seen that employment rates are lower for the less educated. Correspondingly, retirement rates are generally larger among the less educated. Of workers who completed the basic track, about 5.5 percent retire annually, whereas of workers who completed academic track, only 4.7 percent retire annually. As we have seen above, differences in average inclusive option values across education groups are substantial (see Figure $5 \mathrm{~d}$ ), reflecting well-known differences in lifetime income by education group.

--- about here Table 8 --- 
In terms of the strength of the option value effect on retirement rates, we find sizeable differences across education groups and across specifications. When estimating the percentage point effect of a 10,000 util increase using our standard specification (4), the size of the coefficient drops from 5.1 percentage points among basic track graduates to 2.4 percentage points among academic track graduates. However, when we standardize the effect size for instance by looking at the effect of one within education group standard deviation increase in future lifetime utility, we tend to find the opposite result: academic and intermediate track graduates actually become more responsive than basic track graduates. This can be partly explained by the fact that the standard deviation in the utility gain is nearly twice as large in the highest than in the lowest education group. Also when we look at the effect of a hundred percent lifetime utility gain, it is stronger among the better educated than among the less educated.

\section{Understanding the results and their implications}

After having established that the health and financial incentive effects are qualitatively similar in the two data sets, we now exploit the longer time horizon and the richer policy variation in the SOEP data to better understand the implications of our results for pension policy.

\subsection{The Model Fit}

Our first step in understanding the above results is to show how well our estimated models fit the actual retirement behavior. Figure 6 compares, separately for men and women, the actual and predicted retirement hazard rates and the actual and predicted labor force survival rates (starting at age 50). Note that the $y$-axis for hazard rates is in logarithmic scale. Both actual and predicted log retirement rates are practically the same. This was to be expected since our preferred regression specification contains age dummies interacted with sex that should be able to pick up much of the variation in retirement across the age distribution. Hazard rates increase almost linearly until age 65. In other words, retirement hazards increase exponentially with age. The spikes at younger ages are due to sampling variation, but the spikes at older ages $(60,63$ or 65$)$ can be explained by the provisions of the pension system. At age 60 many women could retire on old-age pensions for women and men could retire on either old-age pensions for the unemployed or for the disabled. 65 is the regular retirement age.

--- about here Figure 6 --- 
Figure 6, panels (e) to (h) show predicted retirement hazard rates for men and women by health quintile and by education. Again this is shown on a log scale. The figures show that the main difference in retirement rates is between the first (least healthy) health index quintile and the other health quintiles. This holds across the entire age range but seems to be particularly pronounced below the age of 60, i.e. where the most salient early retirement option is DI. Differences in predicted retirement hazards by age clearly also show an education gradient. Academic track graduates have the lowest retirement hazards across most of the age distribution. The difference is very pronounced among men. In contrast, there is hardly any difference among women older than 56.

\subsection{Relationship between OVs and retirement}

We have seen above that the average inclusive option values are always positive. Thus on average, there are at every age financial incentives to continue working. Another way to study the relationship between option values and retirement behavior is to find - for each individual - the age at which the incentive to retire reaches a maximum (hence the inclusive option value reaches a minimum) and to compute the cumulative proportion of respondents who have reached that age. Then we compare this proportion with the cumulative proportion of individuals who have retired. If reaching the minimum of one's option value to postpone retirement affected actual retirement behavior strongly, we should see something like a one-to-one relationship between the two series. Figure 7 shows that the two series are positively related but at the end of the observation period (at age 69 ) only $20 \%$ of individuals have reached their OV minimum whereas more than $90 \%$ have retired. Thus the predictive value of the OV for aggregate retirement rates seems limited.

--- about here Figure 7 ---

\subsection{Simulation of pension reform}

In this section we show the result of a number of simulated changes to the pension system and compare them to the status quo. We will simulate four different scenarios by varying the option value to postpone retirement for each individual. First, we assume that everyone is able to retire on DI if they want to (maximum lenience), by giving a weight of one to the DI path and zero weight to the alternatives ("100\% DI probability"). Second, we simulate the other extreme by taking away the possibility to retire on DI completely and giving zero weight to the DI path in the inclusive option value ("0\% DI probability", maximum stringency). Since in contrast to e.g. the U.S., we have more 
than two retirement paths, it is not a priori clear how to distribute the DI probability that prevails in the status quo to the other two paths. One possibility is to change the probabilities of the unemployment and the old-age pension path so that they remain proportional to the status quo. $\mathrm{A}$ behavioral interpretation of this possibility is that workers who are denied the DI path will partly choose the UB path and partly chose the OA path. We believe this is unrealistic. Rather, we think that workers will try to get on the "next best" retirement path, which is UB. Thus in the $0 \%$ DI probability scenario, we keep the original OA weight constant but increase the UB weight.

--- about here Figure 8 ---

Further, we model two intermediate scenarios by assuming a one third and a two thirds probability of receiving DI upon application. Again, this begs the question how to choose the relative weights of the two other paths. We illustrate our modeling decision in Figure 8. The $x$-axis shows the assumed variation in DI probabilities and the $y$-axis the implied DI, OA, and UB pathway probabilities. The vertical line shows the overall status quo probabilities. Starting from the status quo and increasing the stringency of the award process means going left, decreasing stringency means going right. When we increase the stringency, we assume that all workers who are denied DI consider taking the UB path instead. When we reduce the stringency, we assume that first workers who would otherwise have taken the "next best" UB path will consider DI. Only if there are no workers left from the UB path, workers who have taken the OA path consider taking the DI path.

Retirement hazards and labor force survival rates are predicted using our baseline estimation equation (specification 4 in Table 4). The results of our simulations can be seen in Figure 9. Retirement hazard rates are largest under a "100\% DI probability" regime and smallest under a "0\% DI probability" regime. The other regimes are in between.

--- about here Figure 9 ---

To summarize the data shown in Figure 9, we summed up the survival rates from age 50 to age 69 to get at the expected number of working years at age 50 associated with each scenario. This is shown in Table 8, Part (a). The average number of working years over the 50-69 age interval in our sample is 11.5 years among men and 11 years among women, which implies an average retirement age of 61.5 and 61 years, respectively. Note that this is very close to the average in administrative data as shown in Figure $\mathrm{A} 1$ in the Appendix. Closing the DI path altogether will increase the number of working years by about 0.6 years among men but only 0.2 years among women. Opening up the DI path for 
everyone, for instance by reducing the stringency of the award process, so that everyone who would apply would be accepted, would decrease the average number of working years by 1.6 years among men and 2.4 years among women. Compared to the overall length of retirement of about 17 years (DRV-Bund 2012), these changes appear to be moderate.

--- about here Table 9 ---

Next, we restrict the sample to group of people who should have the most reason to apply for disability benefits, namely workers in bad health. We do not show hazard rates but report only the average number of working years in association with our scenarios (Table 8, Part (b)). For this analysis, we include only individuals who were in the first health quintile at least once during the entire observation period. As it turns out, however, the estimated effect of changing the stringency of the disability benefits is only slightly smaller than the effect estimated for the full sample. This somewhat unexpected finding may be due to the fact that the common specification used for our simulations does not allow for differences in the size of incentive effects by health status.

\section{Conclusion}

In the light of continuing demographic change and ailing labor markets, pension reform remains high on the political agenda in many countries. Owing to a number of recent reforms, the German pension system appears to be on a more financially sustainable path today than it used to be 10 or 15 years ago. However, these reforms have reduced the generosity of the pension system and thus rescinded what many Germans have been used to view as considerable welfare state achievements. Reducing generosity has two effects on the social security budget (Börsch-Supan et al. 2007): a direct (mechanical) effect, by changing contributions and benefits for a given work history, and an indirect effect through behavioral responses to the reform, i.e. more contributions and less benefits due to longer working lives. These two effects can also be found on the level of the individual worker and their relative strength depends on the elasticity of labor supply, which in turn may depend to a considerable extent on individual health.

The aim of this chapter was to expand and complement earlier micro-simulation studies on the German pension system by a more systematic treatment of health and disability. More than 20 percent of the workforce eligible for public pensions enter retirement first on disability pensions, at an average age of only slightly more than 50 years. While disability uptake rates have been fairly constant in the last three decades, important changes can be found with respect to the type of 
health problems that trigger early retirement. Retirement on disability pensions due to cardiovascular health problems has declined from nearly $40 \%$ to less than $10 \%$ and has been largely replaced by retirement due to mental health problems, which now are the primary diagnosis for disability in more than $40 \%$ of all early retirees (Börsch-Supan and Jürges 2012).

We address two new questions in this chapter: First, to what extent do financial incentives to retire measured by the option value to postpone retirement by one year - affect the retirement decisions of sick or disabled individuals? Put differently, does bad health reduce individual's labor supply elasticity at the extensive margin? The answer to this question has important policy implications. If the sick and disabled are not responsive to financial incentives because their labor supply has become inelastic, policies that aim at reducing the generosity of disability benefits and providing less incentives to retire early are only partially successful. They may primarily hurt those for whom disability pensions are an important part of the welfare system. In contrast, if disability pension recipients respond to reductions in generosity by postponing retirement, these reductions are less harmful than in the first case. Unfortunately, our empirical results with respect to that question are somewhat ambiguous, but the least common denominator is that among the least healthy financial incentives do not matter less than among healthier segments of the workforce.

Given this result, our next question is how do changes to the stringency of the disability award process affect labor supply and average retirement age? To simulate the effect of those changes in stringency, such as stricter medical requirements, can be quite challenging. Therefore, we took a very simple approach and varied the likelihood of receiving disability pensions from zero to 100 percent, i.e. from a totally restrictive to a totally lenient reward process, and compared the average retirement age or the average length of the remaining working life to the status quo. We found that increasing the stringency of the award process so that the DI path is closed altogether will increase the expected retirement age by only 0.6 years among men and 0.2 years among women, based on SOEP data. In contrast, reducing the stringency to the extent every applicant would be accepted, would decrease the average number of working years quite substantially, namely by 1.6 years among men and 2.4 years among women. These simulated changes seem moderate, in particular considering the fact that the SHARE-based elasticities were even smaller. However, what needs to be taken into account is that our simulations make an important assumption: individuals who are denied the DI path consider taking the next best path to early retirement (which is unemployment). Thus making the disability benefit award process more stringent without closing this other fairly generous early retirement route would not greatly increase labor force participation in old age. 
There are several methodological caveats requesting future research. First, the SHARE data exhibit a substantially smaller marginal effect of the option value and at the same time larger effects of the health variables, compared to the estimates based on the SOEP data. This may reflect the more encompassing health measure in the SHARE data. On the other hand, earnings histories are probably better captured by the SOEP data than by SHARELIFE. The SOEP-based estimates of the financial incentives may therefore be an upper bound, while the SHARE-based estimates may rather represent a lower bound.

Second, the utility parameters embedded in the option value have not been estimated but are fixed at values based on earlier US estimates. While this ensures comparability to all other country chapters in this volume, the choice of the parameter describing the value of leisure appears to be very low for European countries. In future work, these parameters should be estimated by maximum likelihood methods.

Third and finally, the chosen functional form of the estimation equation is a combination of a probit model (and its underlying random utility logic) with an option value which has its own utility function embedded, in particular a very specific functional form of the tradeoff between labor and leisure. While this pragmatic approach has worked well in many circumstances, it is not an internally consistent model of labor supply which has failed in other circumstances, see Börsch-Supan (2012). Further research is necessary to shed light on the environments in which our approach is a reliable approximation of an internally consistent model. 


\section{References}

Börsch-Supan, A. and R. Schnabel (1999): Social Security and Retirement in Germany. Ch. 4 in: in: J. Gruber and D. Wise (eds.), Social Security and Retirement around the World. University of Chicago Press

Börsch-Supan, A., R. Schnabel, S. Kohnz, and G. Mastrobuoni (2004): Micro-Modeling of Retirement Decisions in Germany. Ch. 5 in: J. Gruber and D. Wise (eds.), Social Security Programs and Retirement around the World: Micro-Estimation. University of Chicago Press

Börsch-Supan, A. (2005): Work Disability and Health. In: A. Börsch-Supan et al. (eds.), Health, Ageing, and Retirement in Europe - First Results from the Survey of Health, Ageing and Retirement in Europe. Mannheim, pp.253-258.

Börsch-Supan, A. and C. B. Wilke (2007): The German Public Pension System: How it will become an NDC System Look-Alike, In: Robert Holzmann and Edward Palmer (Eds.), Pension Reform Issues and Prospects for Non-Financial Defined Contribution (NDC) Schemes, World Bank, Washington D.C., pp.573-610.

Börsch-Supan, A., S. Kohnz, and R. Schnabel (2007): The Budget Impact of Reduced Early Retirement Incentives on the German Public Pension System. Ch. 5 in: J. Gruber and D. Wise (eds.), Social Security Programs and Retirement around the World: Fiscal Implications of Reform. University of Chicago Press.

Börsch-Supan, A. (2011): Gesamtwirtschaftliche Wirkungen der Rentenreformen, In: Eichenhofer, E., Rische, H. und W. Schmähl (Hrsg.), Handbuch der gesetzlichen Rentenversicherung SGB VI, pp. 251-305.

Börsch-Supan, A. and H. Jürges (2012): Disability, Pension Reform, and Early Retirement in Germany. Ch. 7 in Wise, D. (ed.): Social Security Programs and Retirement around the World: Historical Trends in Mortality and Health, Employment, and Disability Insurance Participation and Reforms. University of Chicago Press.

Börsch-Supan, A. (2012): Note on the Stock-Wise utility function used in their option-value analysis, mimeo, Munich Center for the Economics of Aging, Munich.

Commission for Sustainability in Financing the Social Security Systems (Kommission für die Nachhaltigkeit in der Finanzierung der Sozialen Sicherungssysteme) (2003): Final Report (Abschlußbericht). Bundesministerium für Gesundheit und Soziale Sicherheit, Berlin.

Deutsche Rentenversicherung Bund (2012): Rentenversicherung in Zeitreihen. Ausgabe 2012. DRVSchriften Band 22.

Dustmann, C. (2004): Parental Background, Secondary School Track Choice, and Wages, Oxford Economic Papers, Vol. 56, pp. 209 - 230.

Gruber, J. and D. Wise (2004): Social Security Programs and Retirement around the World: MicroEstimation. University of Chicago Press.

Jürges, Hendrik (2009): Healthy minds in healthy bodies. An international comparison of educationrelated inequality in physical health among older adults. Scottish Journal of Political Economy Vol. 56, No. 3, pp. 296-320.

Jürges, Hendrik and Kerstin Schneider (2011): " Why Young Boys Stumble: Early Tracking, Age and Gender Bias in the German School System. German Economic Review Vol. 12 No. 4, pp. 371394. 
Kemptner, Daniel, Hendrik Jürges, and Steffen Reinhold (2011): Changes in compulsory schooling and the causal effect of education on health: Evidence from Germany. Journal of Health Economics Vol. 30, pp. 340-354.

Little, R. J. A. (1988): Missing-data adjustments in large surveys. Journal of Business and Economic Statistics Vol. 6, pp. 287-296.

Riphahn, Regina T. (1999): "Income and employment effects of health shocks A test case for the German welfare state," Journal of Population Economics, Springer, Vol. 12, No. 3, pp. 363389.

Romeu Gordo, L. (2006): Effects of short- and long-term unemployment on health satisfaction: Evidence from German data, in: Applied Economics, 38. Jg., Nr. 20, S. 2335-2350.

Poterba, J.; S. Venti and D. Wise (2010): The asset cost of poor health. NBER Working Paper 16389.

Schröder, M. (2011): Retrospective Data Collection in the Survey of Health, Ageing and Retirement in Europe. SHARELIFE Methodology. Mannheim: MEA.

Stock, J. H., and D. A. Wise (1990): The pension inducement to retire: An option value analysis. In Issues in the economics of aging, ed. D. A. Wise, 205-30. Chicago: University of Chicago Press.

Wagner, Gert G., Frick, Joachim R., and Schupp, Jürgen (2007): The German Socio-Economic Panel Study (SOEP) - Scope, Evolution and Enhancements, Schmollers Jahrbuch 127 (1), 139-169

Weiss, C. T. (2012): Two measures of lifetime resources for Europe using SHARELIFE. SHARE Working Paper Series 06-2012 


\section{Tables and Figures}

Table 1: Variants pension benefits

\begin{tabular}{|l|l|l|l|l|}
\hline & $\begin{array}{l}\text { Earliest } \\
\text { age }\end{array}$ & Years of contribution & Other & Introduced \\
\hline Disability benefits & No limit & 5 (3 in last 5 years $)$ & $\begin{array}{l}\text { Work capacity less than } 3 \text { hours per day } \\
\text { (less than } 6 \text { for partial DI) }\end{array}$ & 1957 \\
\hline Regular old-age & 65 & 5 & None & 1957 \\
\hline For Unemployed & 60 & $15(8$ in last 10 years $)$ & At least 52 weeks unemployed & 1957 \\
\hline For Women & 60 & $15(10$ after age 40) & & 1957 \\
\hline For Long-term insured & 63 & 35 & Actuarial adjustment since 19xx & 1972 \\
\hline For Disabled Workers & 60 & 35 & No actuarial adjustment & 1972 \\
\hline
\end{tabular}


Table 2: Benefit types, retirement ages and adjustment factors (2010)

\begin{tabular}{|c|c|c|c|c|c|c|c|c|c|c|c|c|c|c|}
\hline \multirow{2}{*}{ Benefit Type } & \multicolumn{14}{|c|}{ Age } \\
\hline & \begin{tabular}{l|l|}
$<\mid 56$ \\
\end{tabular} & 57 & 58 & 59 & 60 & 61 & 62 & 63 & 64 & 65 & 66 & 67 & 68 & 69 \\
\hline \multicolumn{15}{|c|}{ Old age pensions $(\mathrm{OA})$} \\
\hline Regular & & & & & & & & & & 1.000 & 1.060 & 1.120 & 1.180 & 1.240 \\
\hline \multicolumn{15}{|c|}{ Early old-age pensions options (OA) } \\
\hline For long-term employed & & & & & & & & 0.928 & 0.964 & 1.000 & 1.060 & 1.120 & 1.180 & 1.240 \\
\hline For previously unempl. & & & & & 0.820 & 0.856 & 0.892 & 0.928 & 0.964 & 1.000 & 1.060 & 1.120 & 1.180 & 1.240 \\
\hline For the disabled & & & & & 0.892 & 0.928 & 0.964 & 1.000 & 1.000 & 1.000 & 1.060 & 1.120 & 1.180 & 1.240 \\
\hline For women & & & & & 0.820 & 0.856 & 0.892 & 0.928 & 0.964 & 1.000 & 1.060 & 1.120 & 1.180 & 1.240 \\
\hline \multicolumn{15}{|c|}{ Disability pension (DI) } \\
\hline Disability pension &. .0 .892 & 0.892 & 0.892 & 0.892 & 0.892 & 0.928 & 0.964 & 1.000 & 1.000 & 1.000 & 1.060 & 1.120 & 1.180 & 1.240 \\
\hline
\end{tabular}


Table 3: First principle component index of health based on SHARE Germany

\begin{tabular}{lccc}
\multicolumn{1}{c}{ Health measure } & Wave 1 & Wave 2 & Wave 4 \\
\hline \hline Difficulty walking sev blocks & 0.292 & 0.269 & 0.288 \\
Difficulty lift/carry & 0.235 & 0.294 & 0.303 \\
Difficulaty push/pull & 0.260 & 0.287 & 0.311 \\
Difficulty wih an ADL & 0.283 & 0.275 & 0.284 \\
Difficulty climbing stairs & 0.265 & 0.269 & 0.267 \\
Difficulty stoop/kneel/crouch & 0.294 & 0.290 & 0.269 \\
Difficulty getting up from chair & 0.284 & 0.288 & 0.273 \\
Self-reported health fair or poor & 0.294 & 0.274 & 0.269 \\
Difficulty reach/extend arms up & 0.255 & 0.247 & 0.260 \\
Ever experience arthritis & 0.156 & 0.141 & 0.184 \\
Difficulty sitting two hours & 0.218 & 0.231 & 0.171 \\
Difficulty pick up a coin & 0.138 & 0.187 & 0.173 \\
Back problems & 0.190 & 0.172 & 0.151 \\
Ever experience heart problems & 0.157 & 0.167 & 0.156 \\
Hospital stay & 0.157 & 0.161 & 0.153 \\
Doctor visit & 0.226 & 0.197 & 0.210 \\
Ever experience psychological problems & 0.110 & 0.087 & 0.112 \\
Ever experience stroke & 0.131 & 0.132 & 0.124 \\
Ever experience high blood pressure & 0.137 & 0.115 & 0.095 \\
Ever experience lung disease & 0.104 & 0.072 & 0.065 \\
Ever experience diabetes & 0.104 & 0.122 & 0.121 \\
BMl at beginning of obs. Period & 0.092 & 0.080 & 0.116 \\
Nursing Home stay & 0.115 & 0.083 & 0.072 \\
Ever experience cancer & 0.069 & 0.073 & 0.092 \\
\hline \hline $\mathrm{N}$ & 2953 & 2480 & 1489
\end{tabular}

Based on SHARE waves 1, 2 and 4 for Germany 
Table 4: DI Participation by health, education, and sex (age 45-59)

\section{(a) SOEP 1984-2009}

\begin{tabular}{lcrllll}
\hline & \multicolumn{7}{c}{ Men } \\
\cline { 2 - 7 } Education & $\mathbf{1}$ & $\mathbf{2}$ & $\mathbf{3}$ & $\mathbf{4}$ & $\mathbf{5}$ & All \\
\cline { 2 - 7 } & $\mathbf{1}$ & $10.80 \%$ & $6.73 \%$ & $3.33 \%$ & $2.56 \%$ & $9.51 \%$ \\
Basic track & $20.04 \%$ & $6.87 \%$ & $4.57 \%$ & $3.60 \%$ & $2.95 \%$ & $5.83 \%$ \\
Intermediate track & $12.08 \%$ & $1.00 \%$ & $1.85 \%$ & $1.44 \%$ & $0.81 \%$ & $3.25 \%$ \\
Academic track & $11.02 \%$ & $4.00 \%$ & $2.79 \%$ & $2.08 \%$ & $7.19 \%$
\end{tabular}

Women

Education Health Quintile

\begin{tabular}{lclllll} 
& $\mathbf{1}$ & $\mathbf{2}$ & $\mathbf{3}$ & $\mathbf{4}$ & $\mathbf{5}$ & All \\
\cline { 2 - 7 } Basic track & $16.50 \%$ & $7.28 \%$ & $5.21 \%$ & $3.86 \%$ & $5.32 \%$ & $8.44 \%$ \\
Intermediate track & $14.68 \%$ & $5.46 \%$ & $3.43 \%$ & $2.15 \%$ & $3.25 \%$ & $5.61 \%$ \\
Academic track & $11.73 \%$ & $3.66 \%$ & $1.51 \%$ & $1.65 \%$ & $0.38 \%$ & $3.74 \%$ \\
\cline { 2 - 7 } All & $15.49 \%$ & $6.27 \%$ & $4.04 \%$ & $2.93 \%$ & $3.65 \%$ & $6.92 \%$
\end{tabular}

(b) SHARE 2004-2012

Men

$$
\text { Men }
$$

Health Quintile

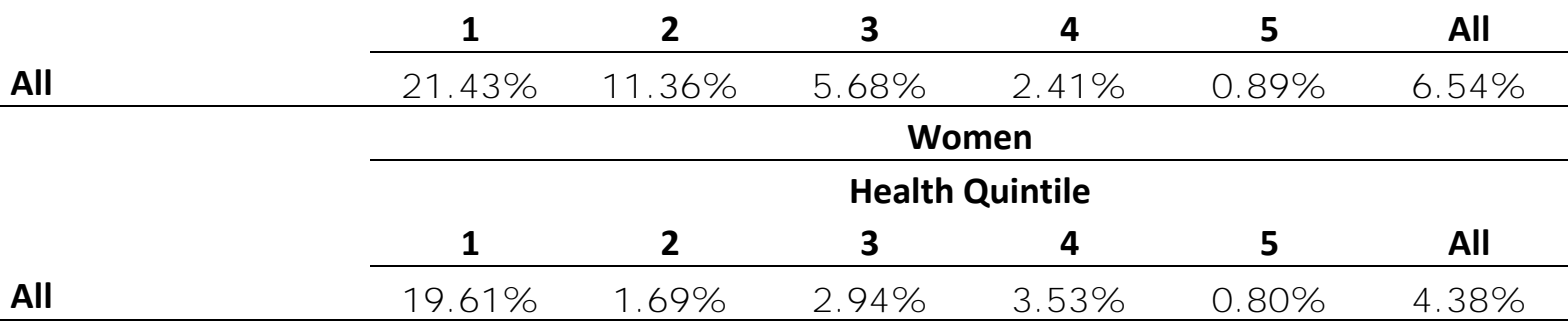


Table 5: Probit regressions explaining the decision to retire (marginal effects), option value enters in absolute value

\begin{tabular}{|c|c|c|c|c|c|}
\hline \multirow[t]{2}{*}{ (a) SOEP } & \multicolumn{5}{|c|}{ Specification } \\
\hline & (1) & $(2)$ & (3) & (4) & $(5)$ \\
\hline \multirow[t]{3}{*}{ Option value $(10,000$ Utils $)$} & -0.0317 & -0.0349 & -0.0379 & -0.0423 & -0.0421 \\
\hline & $(0.0029)$ & $(0.0027)$ & $(0.0034)$ & $(0.0031)$ & (0.0033) \\
\hline & {$[-0.0323]$} & {$[-0.0407]$} & {$[-0.0404]$} & {$[-0.0521]$} & {$[-0.0525]$} \\
\hline \multirow[t]{2}{*}{ Health quintile 2} & -0.0140 & -0.0127 & -0.0136 & -0.0122 & -0.0118 \\
\hline & $(0.0025)$ & $(0.0022)$ & $(0.0024)$ & $(0.0021)$ & $(0.0020)$ \\
\hline \multirow{2}{*}{ Health quintile 3} & -0.0179 & -0.0153 & -0.0173 & -0.0150 & -0.0148 \\
\hline & $(0.0025)$ & $(0.0022)$ & $(0.0024)$ & $(0.0021)$ & $(0.0021)$ \\
\hline \multirow[t]{2}{*}{ Health quintile 4} & -0.0181 & -0.0158 & -0.0170 & -0.0150 & -0.0147 \\
\hline & $(0.0025)$ & $(0.0022)$ & $(0.0024)$ & $(0.0021)$ & $(0.0021)$ \\
\hline \multirow[t]{2}{*}{ Health quintile 5} & -0.0162 & -0.0140 & -0.0153 & -0.0133 & -0.0131 \\
\hline & $(0.0026)$ & $(0.0023)$ & $(0.0025)$ & $(0.0022)$ & $(0.0021)$ \\
\hline Linear Age & $x$ & & $x$ & & \\
\hline Age Dummies & & $x$ & & $x$ & $x$ \\
\hline Age Dummies X Sex & & & & & $x$ \\
\hline Covariates & & & $\mathrm{x}$ & $x$ & $x$ \\
\hline Nobs & 21027 & 20915 & 21027 & 20915 & 20915 \\
\hline Mean retirement rate & 0.052 & 0.053 & 0.052 & 0.053 & 0.053 \\
\hline Mean OV & 13704 & 13771 & 13704 & 13771 & 13771 \\
\hline Std.Dev. OV & 7549 & 7513 & 7549 & 7513 & 7513 \\
\hline
\end{tabular}


Table 5: Probit regressions explaining the decision to retire (marginal effects), option value enters in absolute value

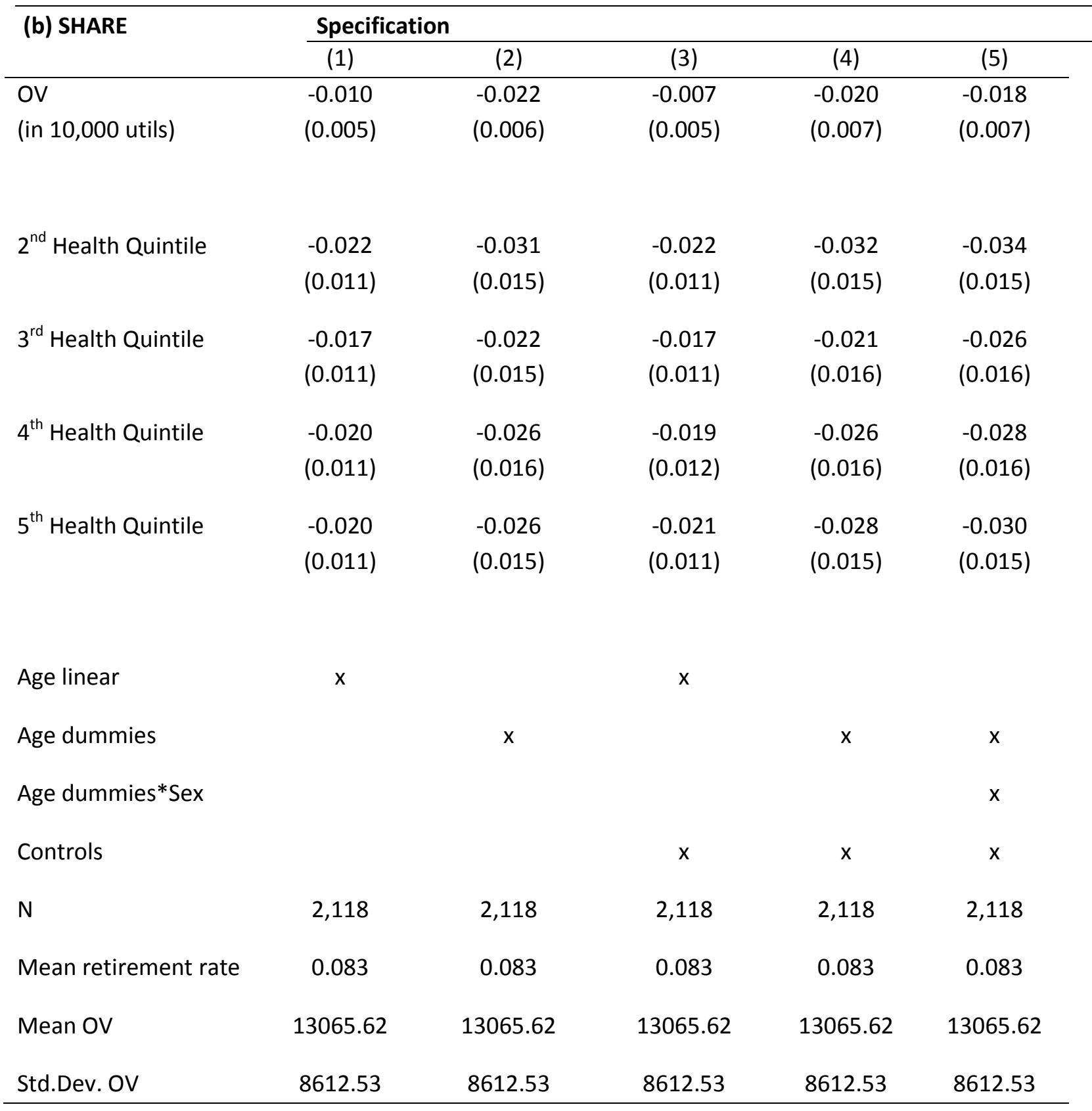


Table 6: Probit regressions explaining the decision to retire (marginal effects), option value enters in relative terms

\begin{tabular}{|c|c|c|c|c|c|}
\hline & \multicolumn{5}{|c|}{ Specification } \\
\hline & (1) & $(2)$ & (3) & (4) & (5) \\
\hline \multirow[t]{2}{*}{ OV utility gain } & -0.0132 & -0.0137 & -0.0130 & -0.0139 & -0.0131 \\
\hline & $(0.0073)$ & $(0.0074)$ & $(0.0074)$ & $(0.0077)$ & (0.0073) \\
\hline \multirow[t]{2}{*}{ Health quintile 2} & -0.0166 & -0.0164 & -0.0162 & -0.0161 & -0.0157 \\
\hline & $(0.0027)$ & $(0.0025)$ & $(0.0027)$ & $(0.0025)$ & $(0.0025)$ \\
\hline \multirow[t]{2}{*}{ Health quintile 3} & -0.0220 & -0.0210 & -0.0209 & -0.0203 & -0.0201 \\
\hline & $(0.0026)$ & $(0.0025)$ & $(0.0026)$ & $(0.0025)$ & $(0.0024)$ \\
\hline \multirow[t]{2}{*}{ Health quintile 4} & -0.0221 & -0.0214 & -0.0208 & -0.0205 & -0.0201 \\
\hline & $(0.0027)$ & $(0.0025)$ & $(0.0026)$ & $(0.0025)$ & $(0.0024)$ \\
\hline \multirow[t]{2}{*}{ Health quintile 5} & -0.0204 & -0.0197 & -0.0191 & -0.0187 & -0.0187 \\
\hline & $(0.0027)$ & $(0.0026)$ & $(0.0027)$ & $(0.0025)$ & $(0.0025)$ \\
\hline Linear Age & $x$ & & $x$ & & \\
\hline Age Dummies & & $x$ & & $x$ & $x$ \\
\hline Age Dummies X Sex & & & & & $x$ \\
\hline Covariates & & & $x$ & $x$ & $x$ \\
\hline Nobs & 21027 & 20915 & 21027 & 20915 & 20915 \\
\hline Mean ret rate & 0.0522 & 0.0525 & 0.0522 & 0.0525 & 0.0525 \\
\hline Mean OV gain & 0.6020 & 0.6050 & 0.6020 & 0.6050 & 0.6050 \\
\hline Std.Dev. OV gain & 0.5404 & 0.5403 & 0.5404 & 0.5403 & 0.5403 \\
\hline
\end{tabular}


Table 7: Marginal effects of inclusive option value on the decision to retire (obtained from probit models), by health quintile

\begin{tabular}{|c|c|c|c|c|c|c|}
\hline & & \multicolumn{5}{|c|}{ Specification } \\
\hline & & (1) & $(2)$ & (3) & (4) & (5) \\
\hline \multirow[t]{5}{*}{ HQ1 } & Option value & -0.0690 & -0.0761 & -0.0792 & -0.0902 & -0.0894 \\
\hline & & $(0.0088)$ & $(0.0086)$ & $(0.0110)$ & (0.0105) & (0.0107) \\
\hline & Std.dev effect & {$[-0.0498]$} & {$[-0.0582]$} & {$[-0.0587]$} & {$[-0.0707]$} & {$[-0.0722]$} \\
\hline & Option value gain & -0.0207 & -0.0221 & -0.0146 & -0.0164 & -0.0147 \\
\hline & & $(0.0163)$ & $(0.0163)$ & $(0.0151)$ & $(0.0152)$ & $(0.0142)$ \\
\hline \multirow{5}{*}{$\mathrm{HQ2}$} & Option value & -0.0351 & -0.0364 & -0.0439 & -0.0453 & -0.0469 \\
\hline & & $(0.0076)$ & $(0.0068)$ & $(0.0079)$ & $(0.0067)$ & $(0.0074)$ \\
\hline & Std.dev effect & {$[-0.0331]$} & {$[-0.0413]$} & {$[-0.0458]$} & {$[-0.0576]$} & {$[-0.0579]$} \\
\hline & Option value gain & -0.0043 & -0.0046 & -0.0049 & -0.0055 & -0.0062 \\
\hline & & $(0.0099)$ & $(0.0093)$ & $(0.0091)$ & $(0.0088)$ & $(0.0085)$ \\
\hline \multirow[t]{5}{*}{ HQ3 } & Option value & -0.0296 & -0.0272 & -0.0314 & -0.0285 & -0.0123 \\
\hline & & $(0.0040)$ & (0.0039) & $(0.0045)$ & $(0.0043)$ & $(0.0029)$ \\
\hline & Std.dev effect & {$[-0.0369]$} & {$[-0.0508]$} & {$[-0.0444]$} & {$[-0.0628]$} & {$[-0.0722]$} \\
\hline & Option value gain & -0.0232 & -0.0230 & -0.0206 & -0.0214 & -0.0111 \\
\hline & & $(0.0132)$ & $(0.0119)$ & $(0.0133)$ & $(0.0122)$ & $(0.0056)$ \\
\hline \multirow[t]{5}{*}{ HQ4 } & Option value & -0.0155 & -0.0173 & -0.0173 & -0.0195 & -0.0235 \\
\hline & & $(0.0050)$ & $(0.0044)$ & $(0.0058)$ & $(0.0050)$ & $(0.0066)$ \\
\hline & Std.dev effect & {$[-0.0369]$} & {$[-0.0508]$} & {$[-0.0444]$} & {$[-0.0628]$} & {$[-0.0722]$} \\
\hline & Option value gain & -0.0199 & -0.0196 & -0.0203 & -0.0203 & -0.0234 \\
\hline & & $(0.0091)$ & $(0.0083)$ & $(0.0097)$ & $(0.0088)$ & $(0.0104)$ \\
\hline \multirow[t]{5}{*}{ HQ5 } & Option value & -0.0151 & -0.0158 & -0.0219 & -0.0219 & -0.0123 \\
\hline & & $(0.0053)$ & $(0.0049)$ & $(0.0057)$ & $(0.0050)$ & $(0.0031)$ \\
\hline & Std.dev effect & {$[-0.0189]$} & {$[-0.0268]$} & {$[-0.0218]$} & {$[-0.0320]$} & {$[-0.0341]$} \\
\hline & Option value gain & -0.0193 & -0.0179 & -0.0272 & -0.0248 & -0.0139 \\
\hline & & (0.0088) & (0.0080) & (0.0097) & $(0.0086)$ & $(0.0051)$ \\
\hline
\end{tabular}


Table 8: Marginal effects of inclusive option value on the decision to retire (obtained from probit models), by education

\begin{tabular}{|c|c|c|c|c|c|c|}
\hline & & \multicolumn{5}{|c|}{ Specification } \\
\hline & & (1) & $(2)$ & (3) & (4) & (5) \\
\hline \multirow[t]{5}{*}{ Basic } & Option value & -0.0344 & -0.0392 & -0.0471 & -0.0511 & -0.0504 \\
\hline & & $(0.0062)$ & $(0.0063)$ & $(0.0068)$ & $(0.0067)$ & $(0.0072)$ \\
\hline & Std.dev effect & -0.0240 & -0.0291 & -0.0340 & -0.0391 & -0.0394 \\
\hline & Option value gain & -0.0063 & -0.0068 & -0.0069 & -0.0069 & -0.0064 \\
\hline & & $(0.0067)$ & $(0.0070)$ & $(0.0071)$ & $(0.0073)$ & $(0.0065)$ \\
\hline \multirow[t]{5}{*}{ Intermediate } & Option value & -0.0415 & -0.0409 & -0.0467 & -0.0457 & -0.0423 \\
\hline & & $(0.0050)$ & $(0.0047)$ & $(0.0051)$ & $(0.0049)$ & $(0.0050)$ \\
\hline & Std.dev effect & -0.0477 & -0.0518 & -0.0592 & -0.0627 & -0.0615 \\
\hline & Option value gain & -0.0205 & -0.0212 & -0.0238 & -0.0254 & -0.0228 \\
\hline & & $(0.0125)$ & $(0.0122)$ & $(0.0135)$ & $(0.0134)$ & $(0.0125)$ \\
\hline \multirow[t]{5}{*}{ Academic } & Option value & -0.0270 & -0.0230 & -0.0296 & -0.0238 & -0.0171 \\
\hline & & $(0.0044)$ & $(0.0033)$ & $(0.0046)$ & $(0.0034)$ & $(0.0027)$ \\
\hline & Std.dev effect & -0.0406 & -0.0620 & -0.0463 & -0.0686 & -0.0734 \\
\hline & Option value gain & -0.0505 & -0.0387 & -0.0512 & -0.0398 & -0.0298 \\
\hline & & $(0.0220)$ & $(0.0172)$ & (0.0209) & $(0.0159)$ & $(0.0116)$ \\
\hline
\end{tabular}


Table 9: Expected years of work (at age 50 ) under various scenarios

\begin{tabular}{|c|c|c|c|c|c|}
\hline & Status Quo & $\begin{array}{l}0 \% \mathrm{DI} \\
\text { prob. }\end{array}$ & $\begin{array}{l}1 / 3 \mathrm{DI} \\
\text { prob. }\end{array}$ & $\begin{array}{l}2 / 3 \mathrm{DI} \\
\text { prob. }\end{array}$ & $\begin{array}{r}100 \% \mathrm{DI} \\
\text { prob. }\end{array}$ \\
\hline \multicolumn{6}{|l|}{ (a) Full sample } \\
\hline \multicolumn{6}{|l|}{ Men } \\
\hline Expected Years of Work & 11.49 & 12.13 & 11.68 & 11.29 & 9.94 \\
\hline Abs. Diff. W.r.t. Status Quo & & 0.64 & 0.19 & -0.20 & -1.55 \\
\hline Rel. change w.r.t. Status Quo & & 1.06 & 1.02 & 0.98 & 0.87 \\
\hline \multicolumn{6}{|l|}{ Women } \\
\hline Expected Years of Work & 11.41 & 11.58 & 11.33 & 10.15 & 9.05 \\
\hline Abs. Diff. W.r.t. Status Quo & & 0.17 & -0.09 & -1.26 & -2.36 \\
\hline Rel. change w.r.t. Status Quo & & 1.01 & 0.99 & 0.89 & 0.79 \\
\hline \multicolumn{6}{|l|}{ (b) Ever in first health quintile } \\
\hline \multicolumn{6}{|l|}{ Men } \\
\hline Expected Years of Work & 11.01 & 11.81 & 11.32 & 10.80 & 9.46 \\
\hline Abs. Diff. W.r.t. Status Quo & & 0.80 & 0.31 & -0.21 & -1.55 \\
\hline Rel. change w.r.t. Status Quo & & 1.07 & 1.03 & 0.98 & 0.86 \\
\hline \multicolumn{6}{|l|}{ Women } \\
\hline Expected Years of Work & 10.99 & 11.15 & 10.88 & 9.61 & 8.46 \\
\hline Abs. Diff. W.r.t. Status Quo & & 0.16 & -0.11 & -1.38 & -2.53 \\
\hline Rel. change w.r.t. Status Quo & & 1.01 & 0.99 & 0.87 & 0.77 \\
\hline
\end{tabular}


(a) by sex

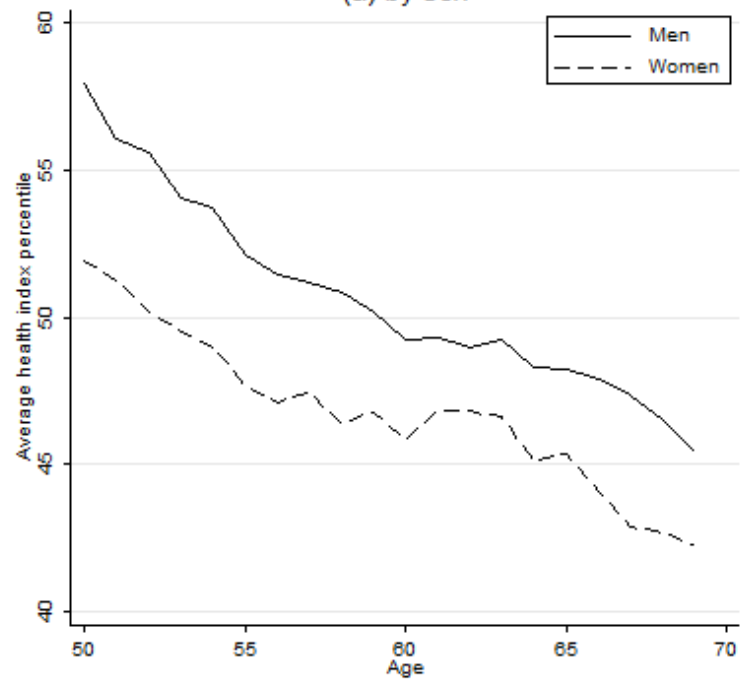

(b) by education

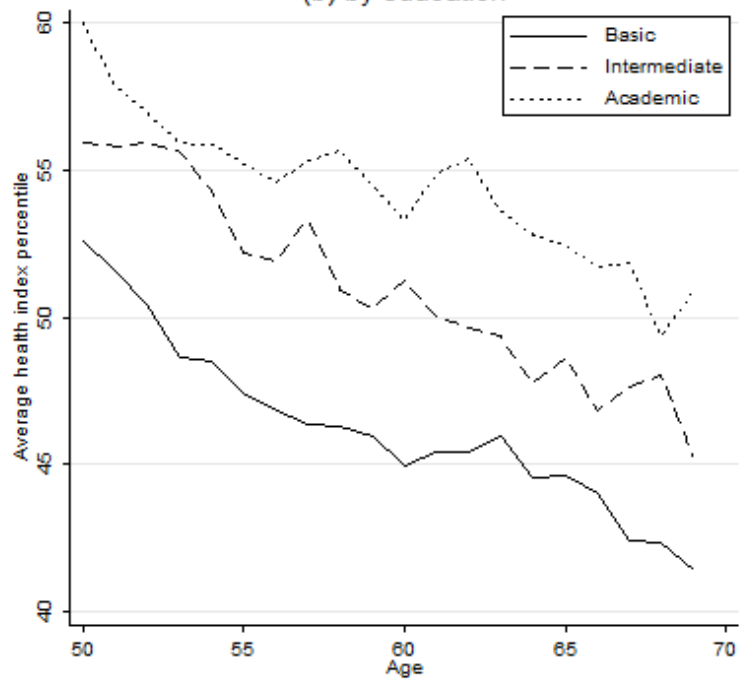

Figure 1: Average health percentile by age and sex. 
(a) DI participation by age
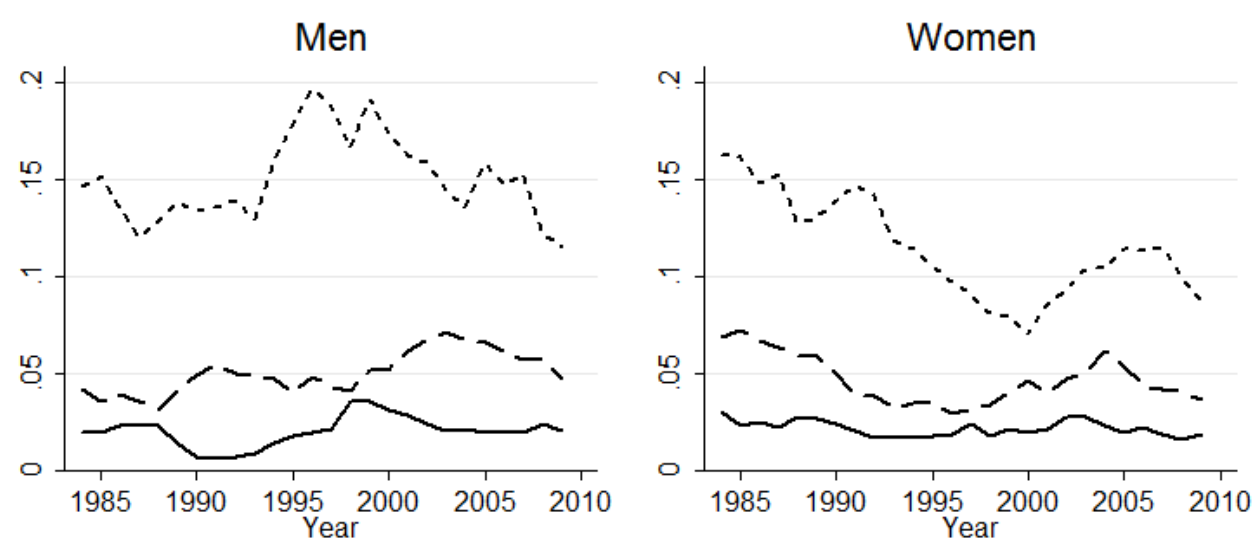

- Age 45-49 — Age 50-54 - . Age 55-59

Age 45-49 - Age 50-54 - - Age 55-59

(b) DI participation by education
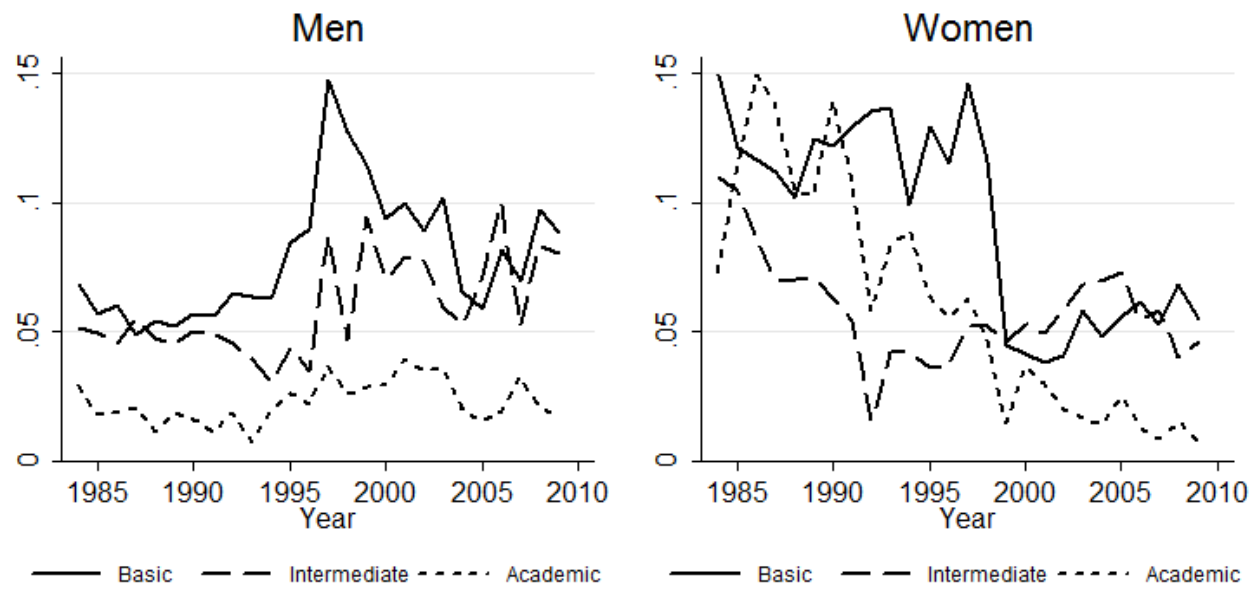

(c) DI participation by health
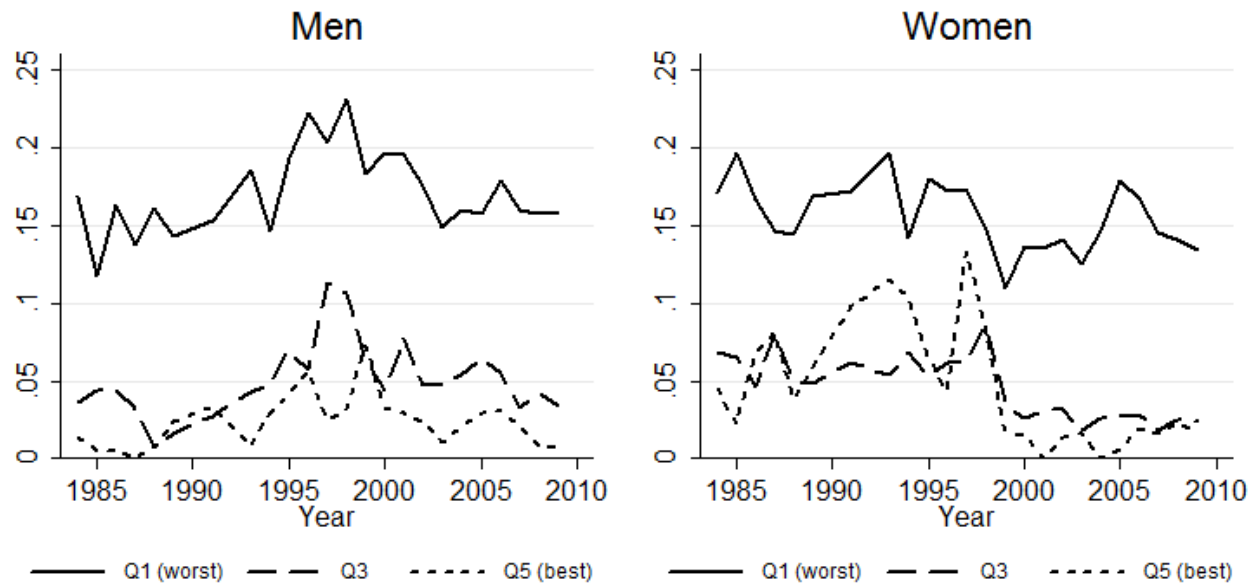

Figure 2: DI participation over time, by sex, age groups, education and health. Source: Own computations using SOEP data. 

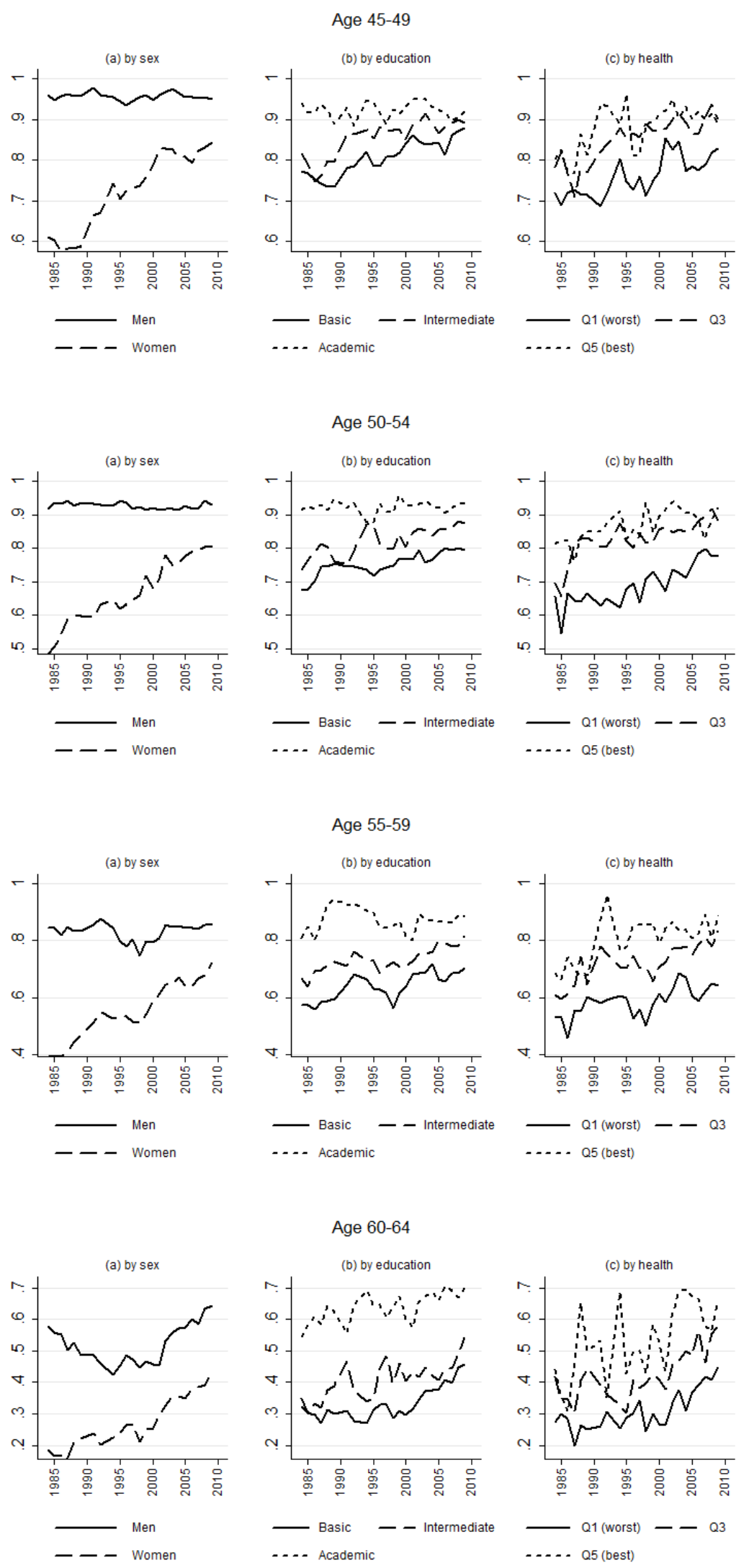

Figure 3: Labor force participation rates at ages 45 to 69 , by sex, education and health quintiles. Source: Own computations using SOEP data. 


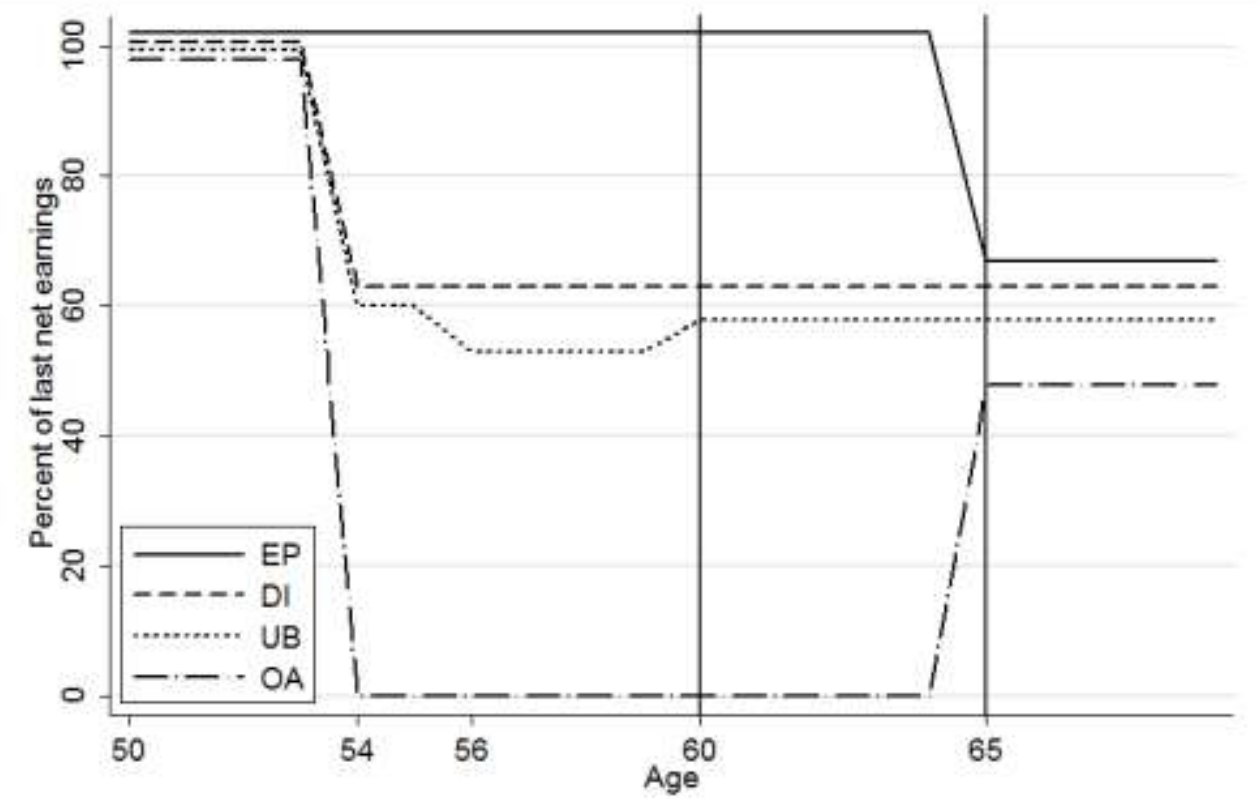

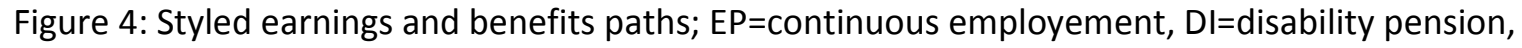
$\mathrm{UB}=$ unemployement benefits, $\mathrm{OA}=\mathrm{old}$-age pension 
(a) Average option values by retirement path
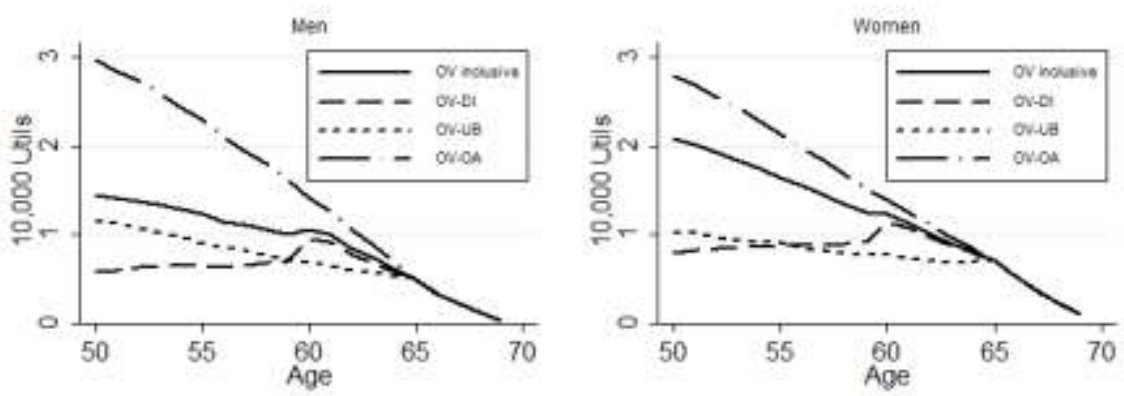

(b) Average present discounted value of income stream by retirement path
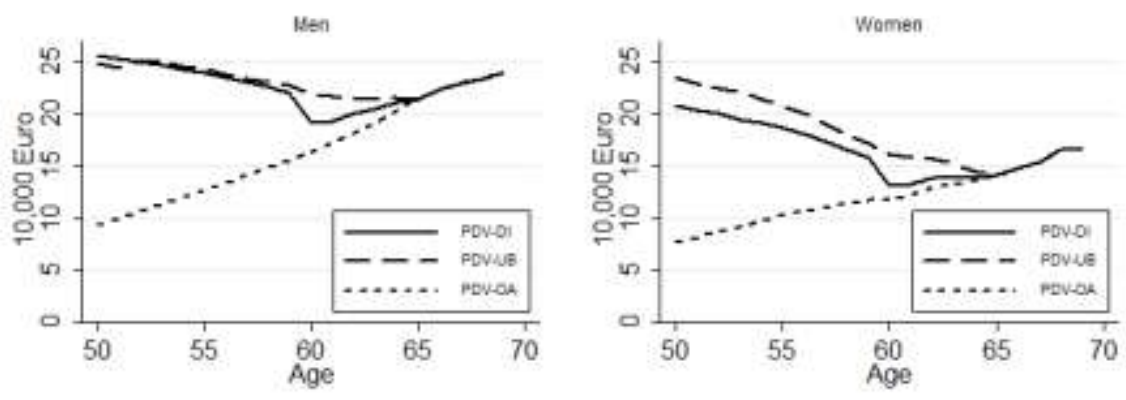

(c) Average inclusive option values by education
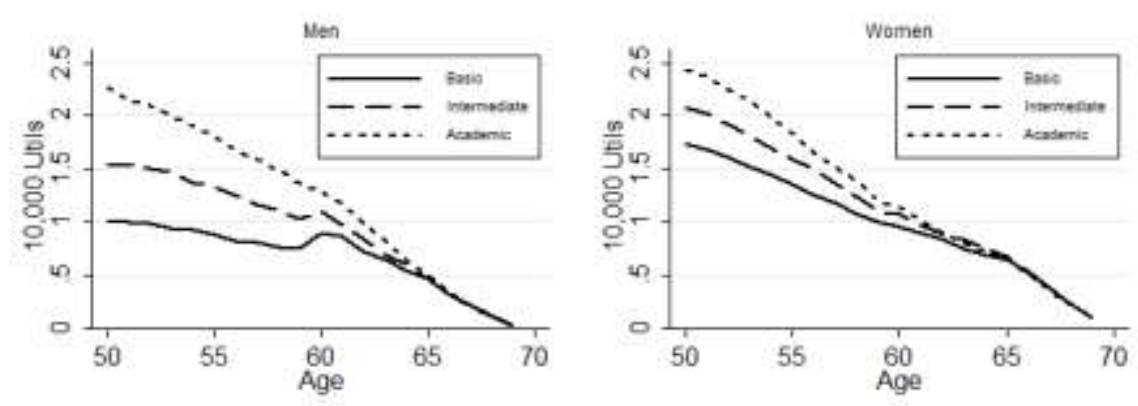

(d) Average inclusive option values by health quintile
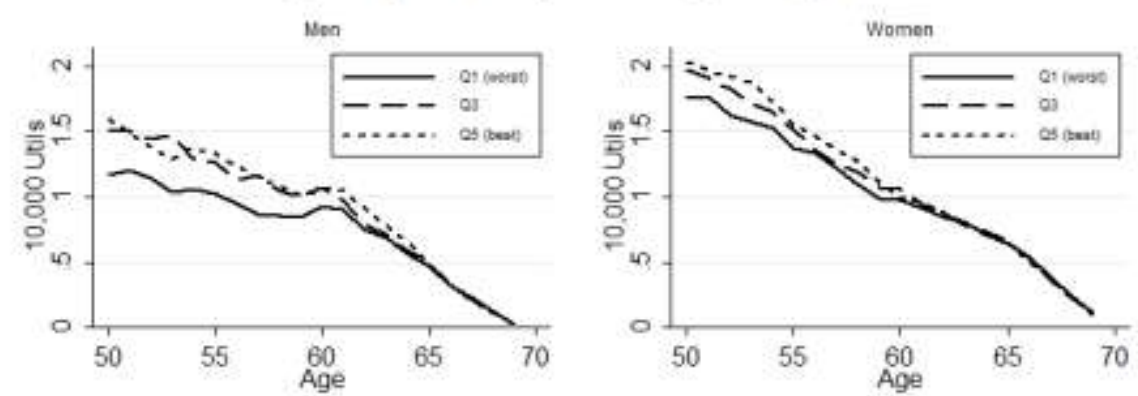

Figure 5: Panel (a): Average option values of postponing retirement via disability (DI), unemployment (UB), or old-age pension (OA) path at planning ages from 50 to 69. Panel (b): Average present discounted values of earnings/benefit streams when retiring via disability (DI), unemployment (UB), or old-age pension (OA) path at planning ages from 50 to 69. Panel (c) and (d): Average inclusive option value, by education and health quintile. 
(a) Hazard Rates, Men

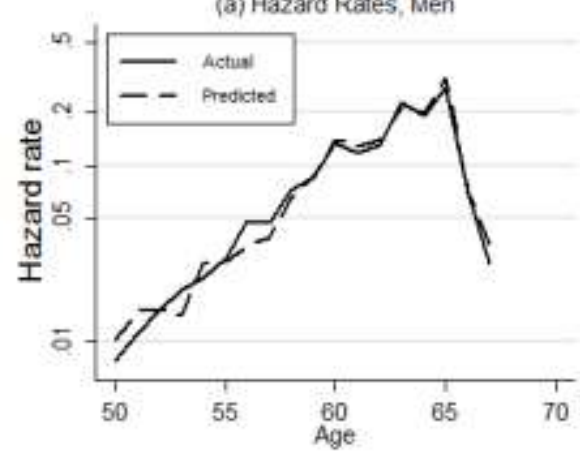

(c) Survival Rates, Men

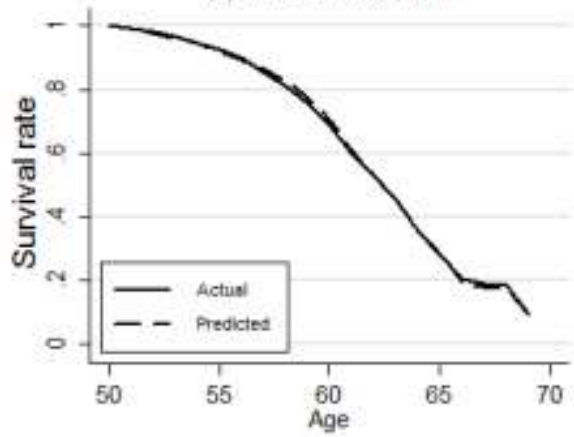

(e) Hazard Rates by Health. Men
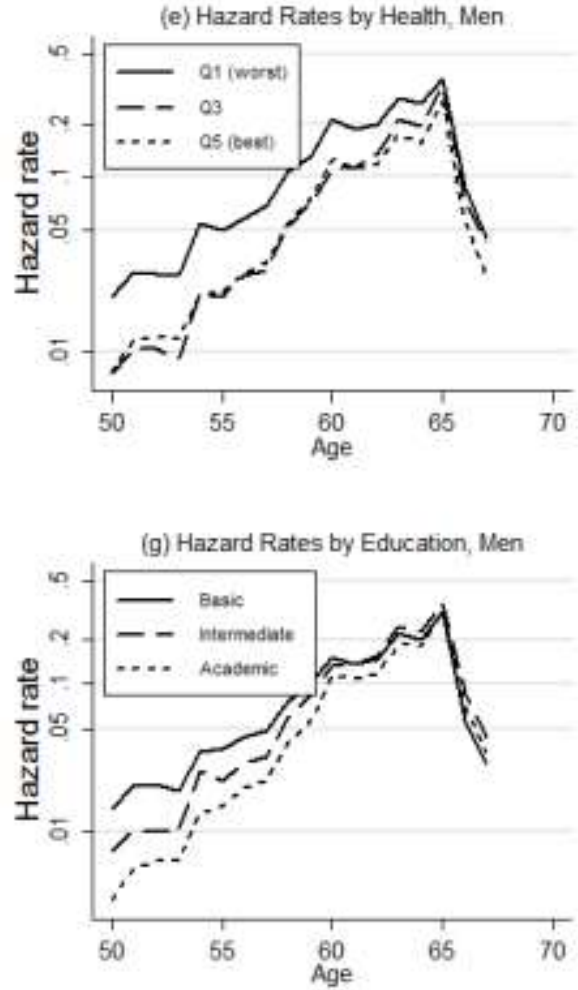

(b) Hazard Rates, Women

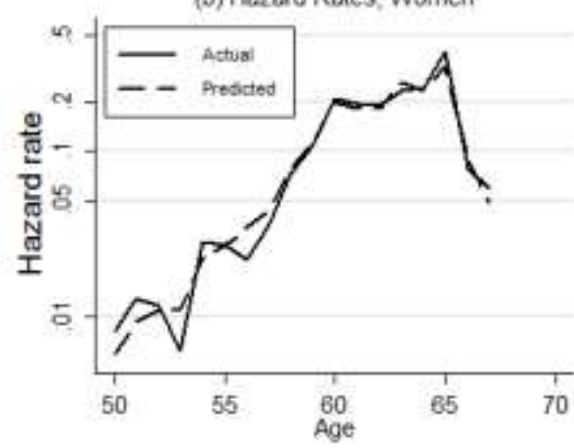

(d) Survival Rates, Women

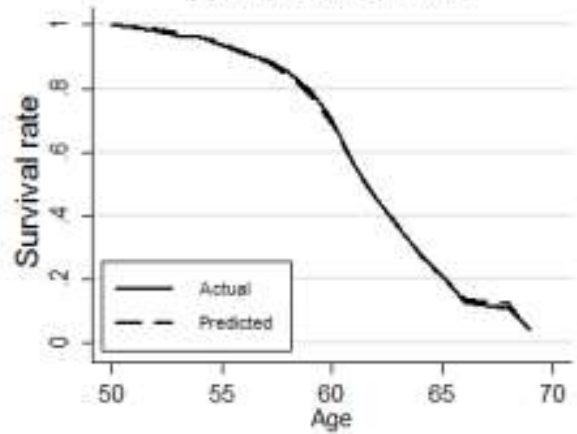

(f) Hazard Rates by Heakh, Women

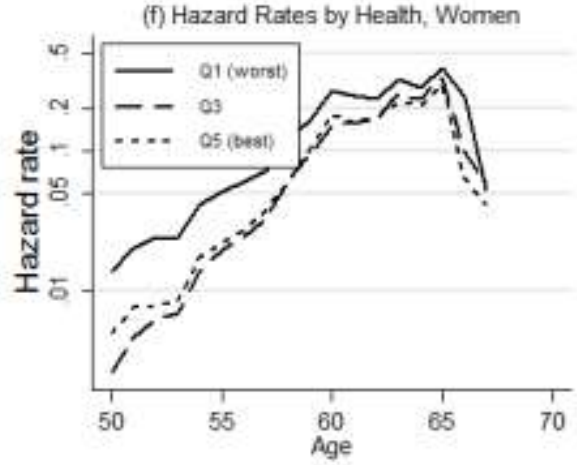

(h) Hazard Rates by Education, Wornen

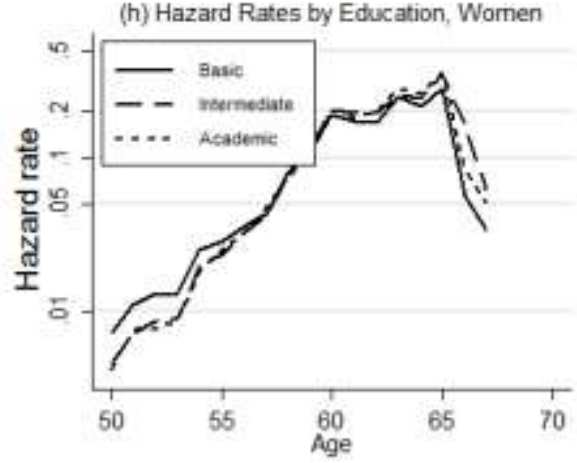

Figure 6: Model fit. Actual versus predicted average retirement rates and survival rates, by sex, education, and health. 


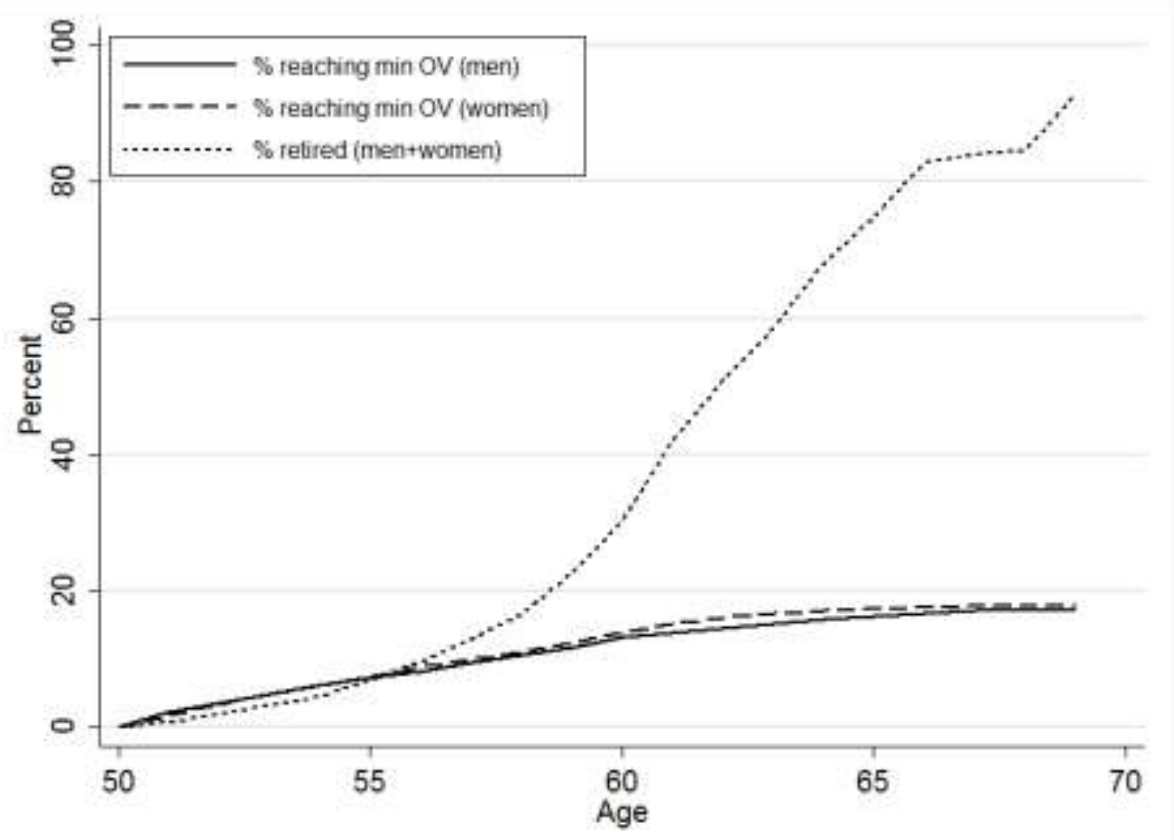

Figure 7: Percent of individuals who have reached the minimum option value (maximum retirement incentive) and actual retirement rate (by age). 


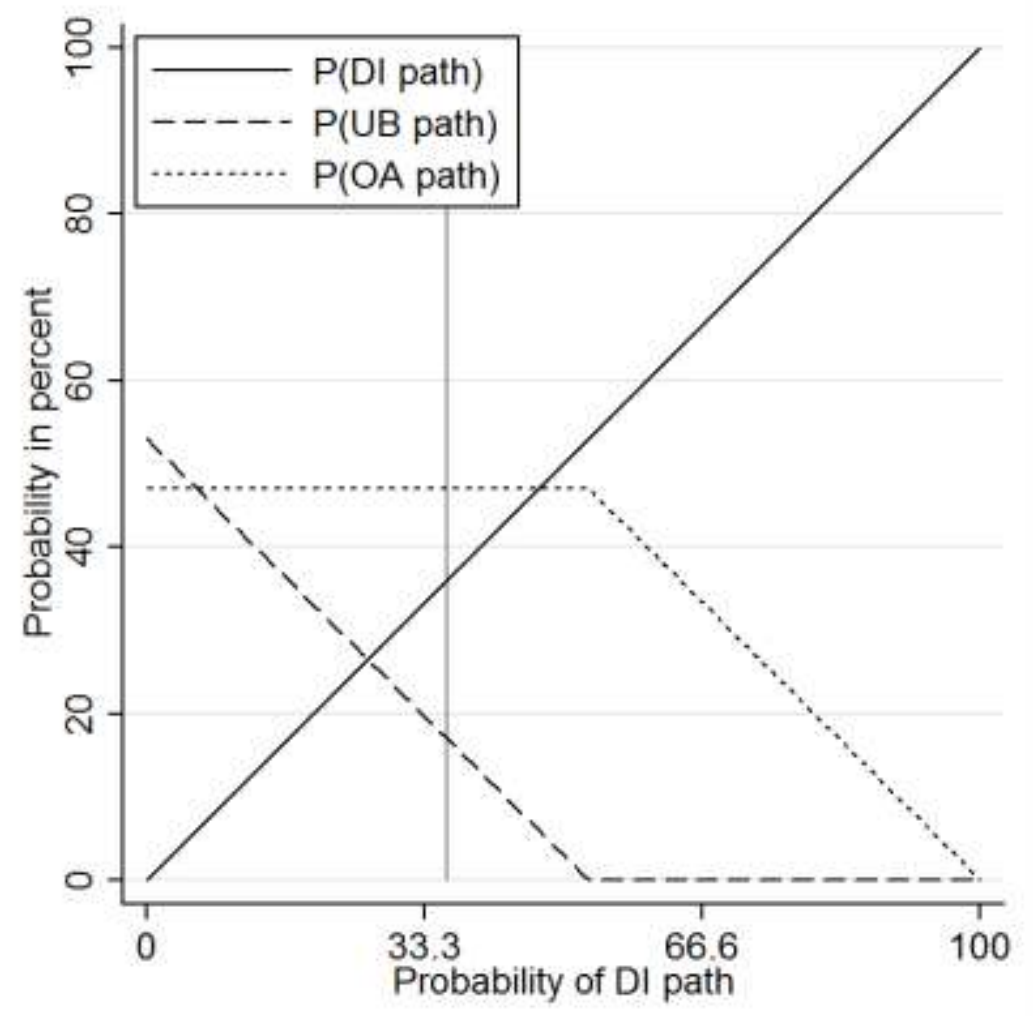

Figure 8: Simulation pathway probabilities 
(a) Hazard rates (log scale)
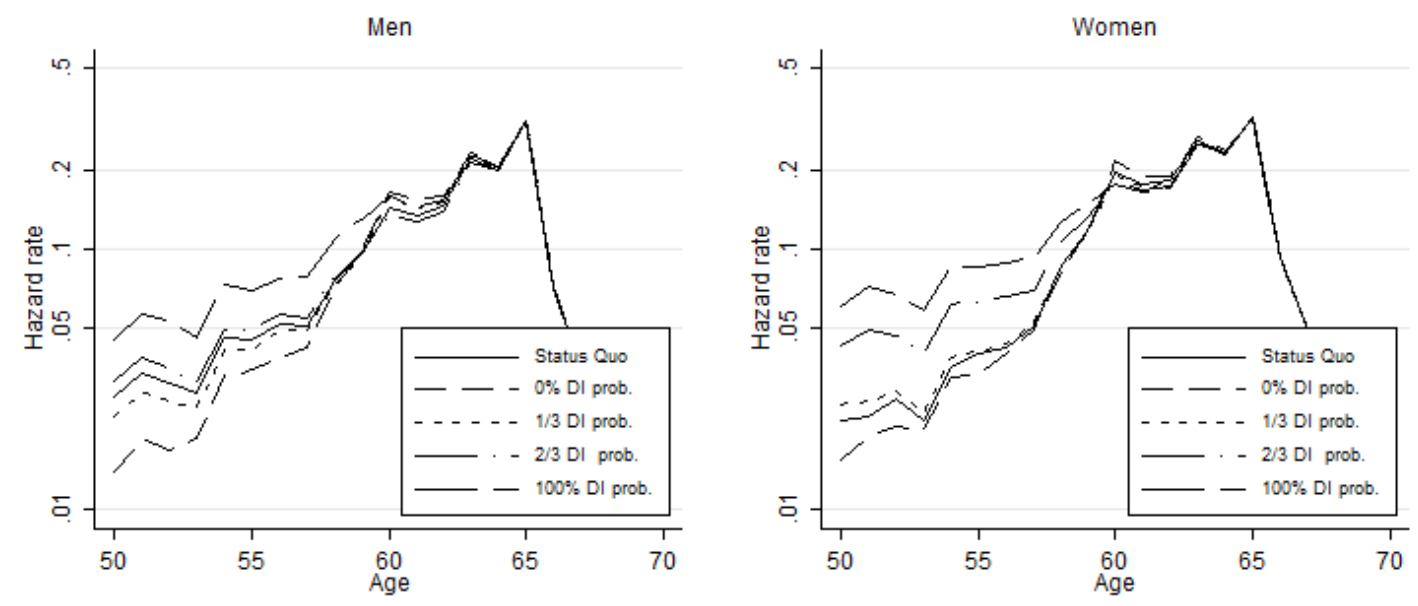

(b) Survival rates
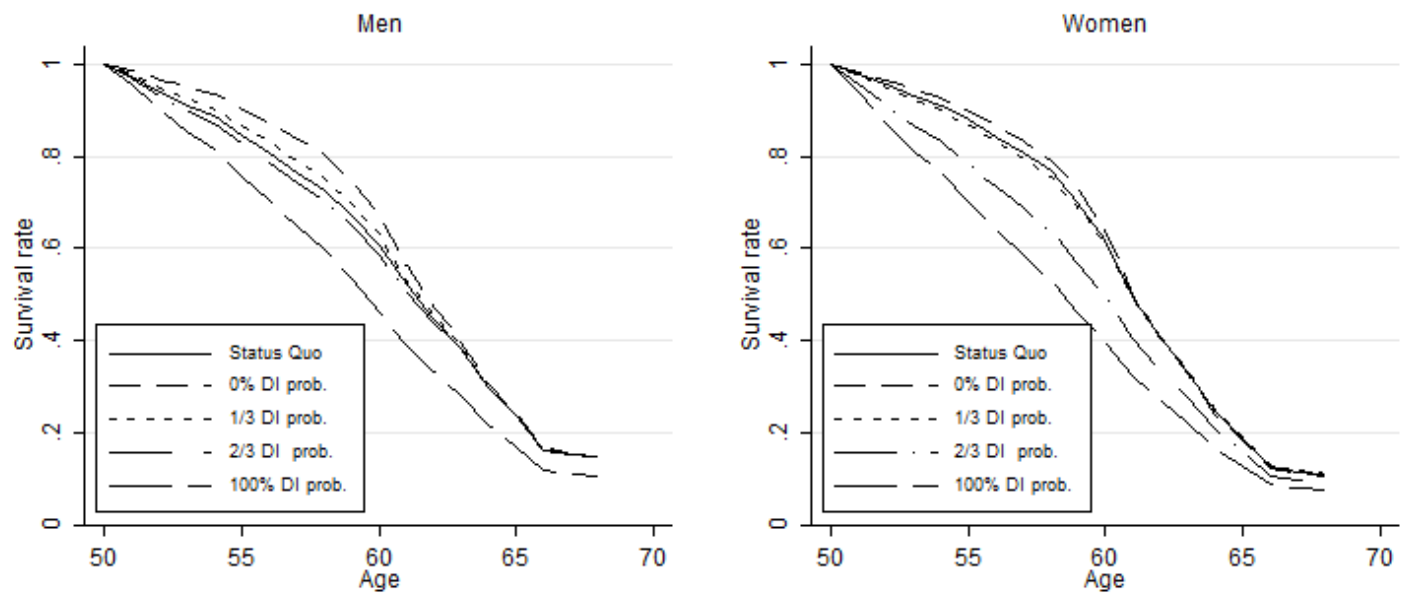

Figure 9: Simulated log hazard and survival rates under different scenarios (all individuals) 


\section{Appendix A}

Table A1: Eligibility for UB1: Maximum number of months, by age and year

\begin{tabular}{|c|c|c|c|c|c|c|c|}
\hline & \multicolumn{7}{|c|}{ Years } \\
\hline Age & until 1984 & 1985 & $1986-87$ & $1988-97$ & $1998-1 / 2006$ & 2/2006-2007 & since 2008 \\
\hline$<45$ & \multirow{16}{*}{12} & \multirow{5}{*}{12} & \multirow{5}{*}{16} & \multirow{5}{*}{22} & 12 & \multirow{11}{*}{12} & \multirow{6}{*}{12} \\
\hline 45 & & & & & \multirow{2}{*}{18} & & \\
\hline 46 & & & & & & & \\
\hline 47 & & & & & \multirow{5}{*}{22} & & \\
\hline 48 & & & & & & & \\
\hline 49 & & \multirow{11}{*}{18} & \multirow{5}{*}{20} & \multirow{5}{*}{26} & & & \\
\hline 50 & & & & & & & \multirow{5}{*}{15} \\
\hline 51 & & & & & & & \\
\hline 52 & & & & & \multirow{5}{*}{26} & & \\
\hline 53 & & & & & & & \\
\hline 54 & & & \multirow{6}{*}{24} & \multirow{6}{*}{32} & & & \\
\hline 55 & & & & & & & \\
\hline 56 & & & & & & & 18 \\
\hline 57 & & & & & & 18 & \\
\hline 58 & & & & & 32 & & 24 \\
\hline$>58$ & & & & & & & \\
\hline
\end{tabular}


Table A2: Retirement rates, by health, education, and sex (age 55-64)

Men

Education

Health Quintile

Basic track

\begin{tabular}{cccccl}
$\mathbf{1}$ & $\mathbf{2}$ & $\mathbf{3}$ & $\mathbf{4}$ & $\mathbf{5}$ & All \\
\hline $46.93 \%$ & $41.38 \%$ & $33.40 \%$ & $27.95 \%$ & $25.75 \%$ & $37.64 \%$ \\
$35.90 \%$ & $30.37 \%$ & $28.79 \%$ & $22.50 \%$ & $21.97 \%$ & $28.30 \%$ \\
$30.98 \%$ & $20.78 \%$ & $18.04 \%$ & $16.46 \%$ & $13.87 \%$ & $19.92 \%$ \\
$42.85 \%$ & $35.61 \%$ & $28.75 \%$ & $23.64 \%$ & $21.62 \%$ & $32.09 \%$
\end{tabular}

$42.85 \%$

$28.75 \%$

Women

Education

Health Quintile

Basic track

\begin{tabular}{cccccl}
$\mathbf{1}$ & $\mathbf{2}$ & $\mathbf{3}$ & $\mathbf{4}$ & $\mathbf{5}$ & All \\
\hline $36.68 \%$ & $29.42 \%$ & $24.63 \%$ & $23.77 \%$ & $23.05 \%$ & $29.37 \%$ \\
$37.95 \%$ & $27.23 \%$ & $24.05 \%$ & $19.97 \%$ & $21.72 \%$ & $27.21 \%$ \\
$33.10 \%$ & $22.56 \%$ & $17.51 \%$ & $15.38 \%$ & $12.47 \%$ & $20.91 \%$ \\
$36.57 \%$ & $28.18 \%$ & $23.52 \%$ & $21.59 \%$ & $20.94 \%$ & $27.86 \%$
\end{tabular}

Notes: calculation combines data from 1984-2009 SOEP. 


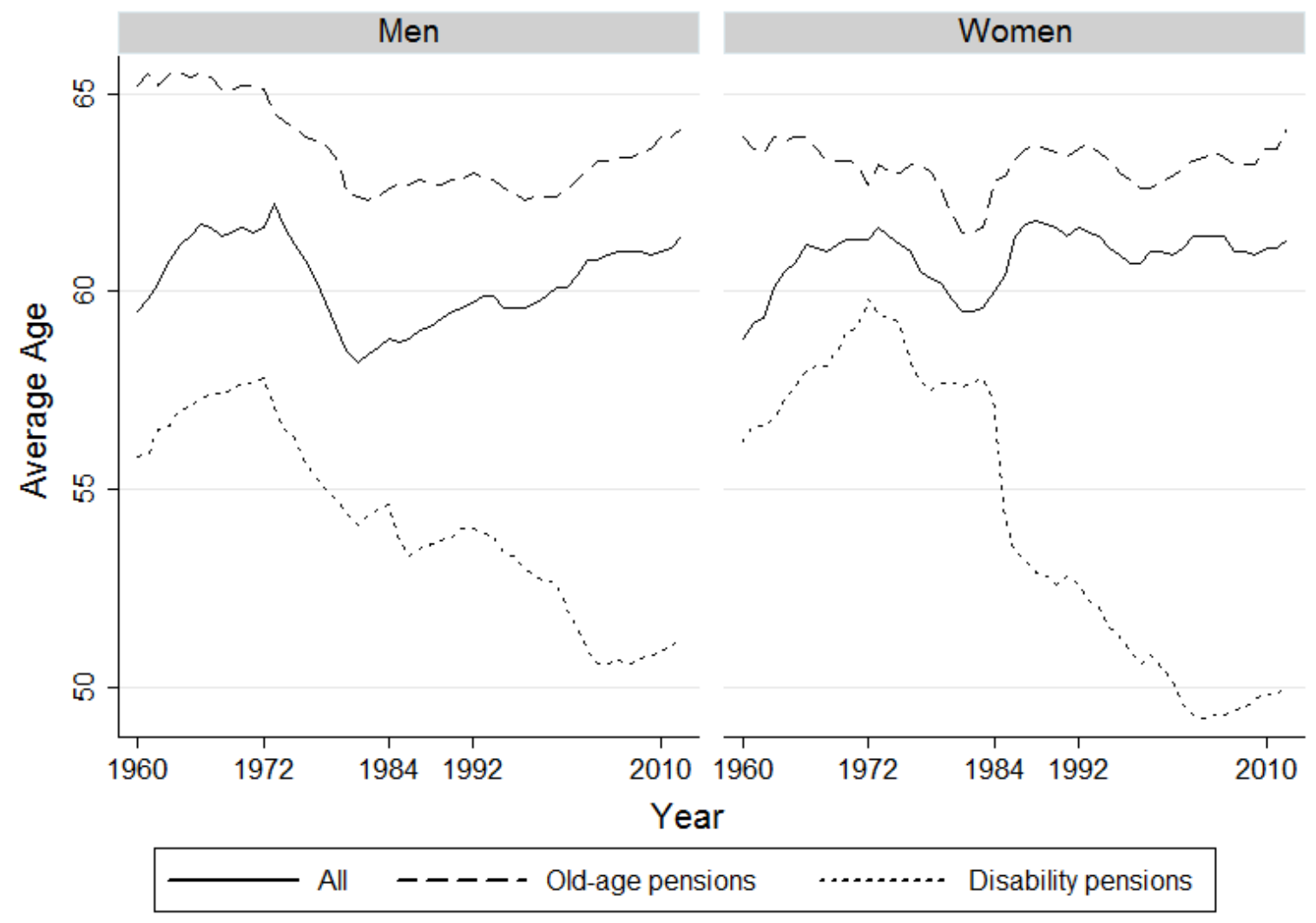

Figure A1: Average retirement ages, West Germany 1960-2012. 
(a) Retirement rates by age
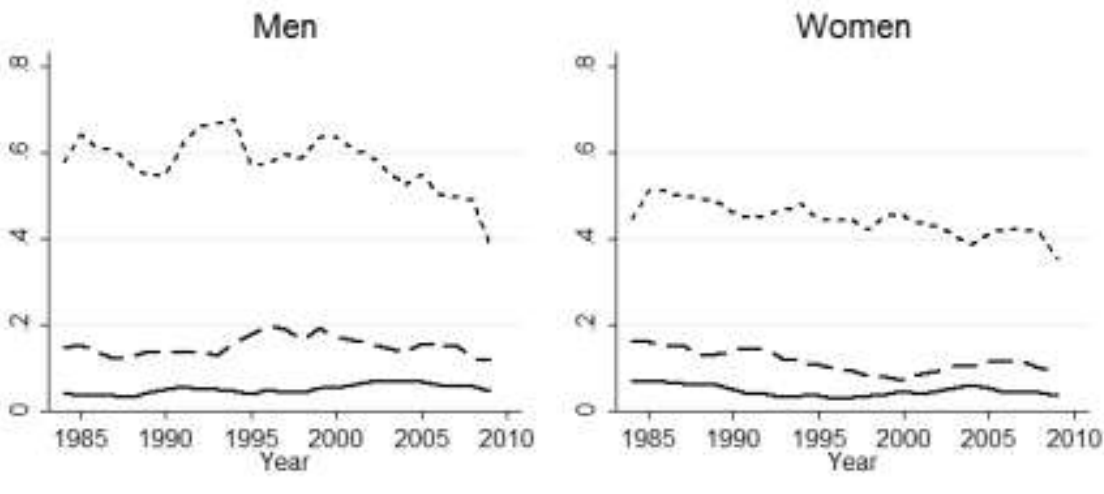

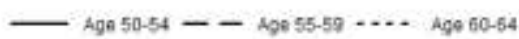

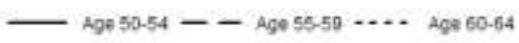

(b) Retirement rates by education (age 55-64)
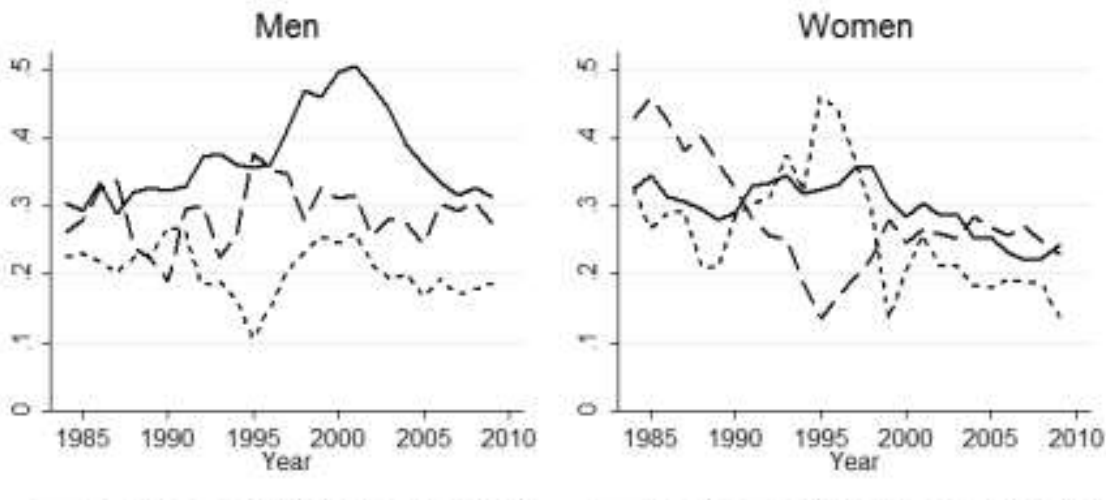

- Basic - - Intermediate...... Acrdemic

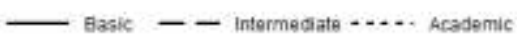

(c) Retirement rates by health (age $55-64$ )
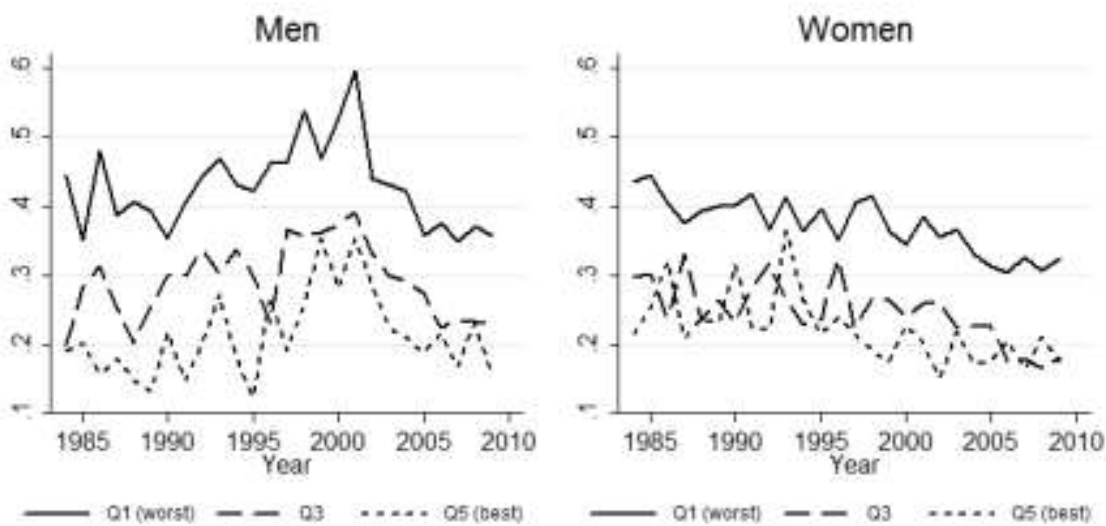

Figure A2: retirement rates over time, by sex, age groups, education and health. Source: Own computations using SOEP data. 